\title{
Combining disparate surveys across time to study satisfaction with life: the effects of study context, sampling method, and transport attributes
}

\author{
Xinyi Wang ${ }^{1}$ (D) F. Atiyya Shaw ${ }^{2}$ (D) Patricia L. Mokhtarian ${ }^{1}\left(\mathbb{D} \cdot\right.$ Giovanni Circella $^{1,3}$ (D) \\ Kari E. Watkins ${ }^{1}$ (D)
}

Accepted: 22 November 2021 / Published online: 3 February 2022

(c) The Author(s) 2022

\begin{abstract}
Satisfaction with life is a self-reported measure of the quality of life that has become a critical societal indicator extensively used for the evaluation and comparison of a wide range of trends and policies. This study fuses five cross-sectional travel surveys conducted from 1992 to 2018 across various geographical locations in California. Using the fused sample, we develop generalized ordered logit models to examine the effects of demographic characteristics, travel-related attributes, general and transport-related attitudinal variables, and context-control variables on individuals' self-reported measures of life satisfaction. We find that longer commute times, mobility limitations, and a tendency to see travel as a waste of time are negatively associated with life satisfaction. To enable the use of disparate cross-sectional survey data, we incorporate context-control variables into the models. We find that life satisfaction appears to be increasing as GDP per capita increases. Among employed people, the macro-scale unemployment rate positively influences their life satisfaction. Interestingly, all else equal, we find that online opinion panel respondents have lower life satisfaction relative to respondents from other sampling methods (mainly address-based sampling), a finding that should be considered in future research using these sampling methods. Overall, this study provides a unique look at life satisfaction within a transport context, while providing an example of fusing small-scale survey datasets to study longitudinal, domain-specific, influences on variables like subjective well-being.
\end{abstract}

Keywords Satisfaction with life $\cdot$ Subjective well-being $\cdot$ Travel behavior $\cdot$ Longitudinal survey $\cdot$ Ordered logit model $\cdot$ Online opinion panel

\section{Introduction}

In 2011, the United Nations General Assembly passed a resolution recognizing happiness and well-being as a fundamental human goal, and followed this in 2013 by establishing an official International Day of Happiness. These actions attracted much

Xinyi Wang

xinyi.wang@gatech.edu

Extended author information available on the last page of the article 
attention from the international community, and especially from those within academia, generating a surge of popular news and academic pieces on well-being and its variants. However, psychologists and social scientists have been studying happiness and subjective well-being (SWB) for decades, based on large-scale longitudinal surveys. For example, Harvard Medical School's Study of Adult Development is the longest-running study of adult life (ongoing since 1939), and focuses on well-being during adulthood (McLaughlin et al. 2010; Waldinger et al. 2007). The World Values Survey (WVS) is another well-known longitudinal study, originating in 1981, spanning almost 100 countries, and spawning numerous contributions to the SWB literature due to its open availability (Kim 2018; Sarracino 2010). Other established sources of longitudinal wellbeing data include the British Social Attitudes Survey (BSA; Dean and Phillips 2015), the European Social Survey (ESS; Welsch and Kuehling 2017), the U.S. General Social Survey (GSS; Ifcher and Zarghamee 2014), and the International Social Survey Program (ISSP; Levin 2014).

These large-scale longitudinal studies have allowed researchers to model the effects of general variables such as demographic characteristics, as well as selected values and behaviors, on SWB. However, because these longitudinal surveys are broad in nature, they do not facilitate the examination of SWB within specific contexts or with the help of more diverse explanatory variables. As a result, researchers within assorted fields have taken to studying SWB using cross-sectional surveys, which are more commonly available and facilitate investigation from specific perspectives (e.g., effects of health, occupation, transportation, etc. on well-being). In this study, we combine the longitudinal and cross-sectional approaches to studying well-being, creating a fused dataset that includes common variables from five travel-behavior-oriented cross-sectional surveys conducted across a 27 -year period. Each survey includes an identical SWB question, as well as numerous other common variables across the individual datasets. Since these surveys were originally designed to serve travel behavior modeling purposes, the development of this fused dataset allows a unique examination of SWB within a transport context. Combining multiple travel survey datasets also enables the analysis of contextual variables that will differ across time and space, leading to more generalizable conclusions about the impact of the transportation-related attributes and attitudes on life satisfaction.

Despite the continuity of some design factors across the five cross-sectional surveys, there are inevitable inconsistencies stemming from question wording differences and evolving survey design techniques over the years. In this study, we demonstrate an approach for addressing and ameliorating such inconsistencies using a combination of survey fusion and model development techniques. As such, one contribution of this work is to provide a rigorous example of using multi-year cross-sectional survey datasets to study the longitudinal evolution of variables, in this case, SWB, over time. Accordingly, this study both: (1) provides a detailed examination of SWB from a general as well as a transportation-oriented perspective; and (2) provides an example of combining cross-sectional survey datasets for longitudinal studies.

The remainder of this paper is organized as follows: the "Literature review" section provides an overview of the SWB literature from both conceptual and empirical perspectives. The "Overview of data" section provides a short introduction to the five transportationoriented surveys, describes the survey fusion framework, and summarizes key statistics across the fused dataset. In the "Model estimation and analysis" section, we briefly provide background on the generalized ordered logit (GOL) model, followed by the results of the GOL models. In the "Discussion" section, we discuss model findings and limitations. We 
conclude with a brief overview of major findings, and provide recommendations for future research.

\section{Literature review}

\section{Conceptual construct: from subjective well-being to life satisfaction}

While the concept of happiness has long fascinated philosophers, positive subjective wellbeing as an academic field of study saw formal and widespread development starting in the 1970s (Diener 1984). As an individualized measurement of well-being (Mokhtarian 2019), SWB serves as a reflector of critical societal metrics such as economic development, social progress, and government policy (Diener 2000). However, the definition and measurement of SWB are more complex relative to traditional social indicators like gross domestic product (GDP). Conceptually, SWB has been defined to have two main components: hedonic and eudaimonic well-being. Hedonic well-being (HWB) refers to pleasure attainment and pain avoidance, while eudaimonic well-being (EWB) is based on the idea of self-actualization (Ryan and Deci 2001). In this study, we focus on a component of SWB, life satisfaction, which represents individuals' conscious evaluation of their lives (Pavot and Diener 1993). Traditionally, life satisfaction has been considered a component of HWB; however, Huta and Ryan (2010) showed that life satisfaction may be related to both hedonic and eudaimonic perspectives of SWB.

Life satisfaction (along with other SWB components) is typically measured using either single-item or multi-item methods, each of which has differing strengths and limitations (Diener 1984). Single-item measures refer to short, clear survey items that can be implemented independently of other items. The simplicity of single-item measures requires less effort from respondents and survey developers, which makes them more suitable for inclusion in non-SWB focused surveys. In contrast, multi-item measures, such as the Satisfaction with Life Scale (SWLS), are composed of a group/set of survey questions, thus allowing researchers to check internal consistency and/or quality of responses, and to obtain a richer, more-nuanced, measure. Recent literature has shown that single-item measures of life satisfaction perform similarly to the multi-item measures in SWLS studies (Atroszko et al. 2017; Cheung and Lucas 2014; Jovanović, 2016); and furthermore, Diener (1984), one of the SWLS developers, recommends the use of single-item scales when a brief measure of global well-being is needed, noting that they provide adequate validity and reliability for such purposes. Accordingly, we use a single item to measure respondents' satisfaction with life, in a series of travel-behavior oriented surveys that will be analyzed in this study.

\section{What influences SWB'? Some empirical results}

Here, we summarize findings from the literature on the effects of (1) demographic characteristics, (2) travel-related attributes, (3) personality and attitudinal variables, and (4)

\footnotetext{
${ }^{1}$ In this section, we use SWB to broadly refer to multiple terms related to well-being evaluations, including subjective well-being, happiness, and life satisfaction. This is largely because scholars often use these terms interchangeably in different domains, thus precluding any attempts to disentangle the results (Gärling and Gamble 2018).
} 
contextual variables (e.g., GDP per capita) on SWB, focusing particularly on these four subgroups of explanatory variables as these were the ones available in the study at hand. Furthermore, many of these variables are commonly studied explanatory factors for life satisfaction in the literature, in addition to domain-specific factors such as health, occupation, and community/friendship. Although the latter have also been found to influence SWB measures, we do not explore them further given that they are not within the scope of this study.

\section{Demographic characteristics}

Behavioral researchers across disciplines often begin their modeling efforts with the inclusion of demographic characteristics, and as evidenced by a wide body of literature, SWB is no exception. Relative to other demographic characteristics, income tends to be of primary interest in SWB studies since it is an indicator of numerous other critical variables such as education (Diener and Biswas-Diener 2002), health (Marmot 2002; Pickett and Wilkinson 2015), and housing (Hansen et al. 1998). In addition, studies have shown that income has interactions with age (Deaton 2008) and household structure (Cracolici et al. 2014; Cummins 2009). As expected, these findings converge on the understanding that income has an overall positive effect on life satisfaction, with higher-income populations having higher levels of well-being, and lower-income populations seeing the greatest potential for increased levels of well-being due to their incompletely met basic living needs (Cheung and Lucas 2014; Deaton 2008; Diener and Oishi 2000; Helliwell and Putnam 2004; Pickett and Wilkinson 2015; Stevenson and Wolfers 2008). In higher-income countries such as the U.S., which is the context of this study, the age effect on SWB has a U-shaped pattern across the life cycle when cohort effects are controlled: i.e., the lowest life satisfaction occurs among the middle-aged population (Blanchflower and Oswald 2008; Deaton 2008; Helliwell and Putnam 2004; Shields et al. 2009; Welsch and Kuehling 2017).

In contrast to the stable patterns identified thus far for income and age, the relationship between SWB and education is less consistent. For example, some studies report that education positively influences SWB, with higher-educated people having higher SWB (Helliwell and Putnam 2004; Nikolaev 2018; Witter et al. 1984; Yakovlev and Leguizamon 2012), while others report negative and/or insignificant effects of education on SWB (Kim 2018; Nikolaev 2015; Shields et al. 2009). Family structure is another key demographic variable, with studies finding that being married increases life satisfaction (Diener et al. 2000; Shields and Wooden 2003), and researchers finding that in general, interactions with family members have positive effects on SWB (Hartley-Clark 2014; Helliwell and Putnam 2004).

\section{Travel-related attributes}

In recent years, SWB has attracted increasing attention in the transportation domain, with De Vos et al. (2013) conceptualizing a seminal framework of ways in which travel behavior may affect SWB, namely via (1) experiences during (destination-oriented) travel, (2) activity participation enabled by travel, (3) activities during (destination-oriented) travel, (4) travel as an activity, and (5) the potential to travel. In practice, the majority of the empirical literature has focused on examining the effects of behavior related to the commute (defined as the trip from home to work/ school, and back) on SWB. 
While numerous studies (Hilbrecht et al. 2014; Martin et al. 2014; Nie and SousaPoza 2016; Stutzer and Frey 2008) have reported that increased commute time is negatively associated with SWB, others (Dickerson et al. 2014; Lorenz 2018) find that commute time is unassociated or even positively associated with SWB. For example, Sweet and Kanaroglou (2016) find that commuting indirectly increases SWB by enabling activity participation. Regarding travel mode, active modes such as cycling and walking are positively related to SWB in general or satisfaction with travel in particular (Martin et al. 2014; Morris and Guerra 2015; St-Louis et al. 2014). In contrast, car commuters have been found to experience increased stress due to mental strain and traffic congestion (Wener and Evans 2011). However, potentially due to differences in local transit services and roadway infrastructure, there are conflicting findings regarding whether car or transit commuters are more satisfied (Eriksson et al. 2013). Nonetheless, among all modes, drivers are least likely to obtain hedonic benefits and most likely to obtain cognitive disadvantages as a result of travel-based multitasking (Shaw et al. 2019). In the same vein, transit passengers are more likely than other mode users to experience both hedonic and productive benefits from travel-based multitasking (Shaw et al. 2019). Thus, we see that the effects of mode choice on SWB can be moderated by mode attributes such as quality of the available service and opportunities for multitasking.

\section{Personality and attitudes}

While we have thus far examined external characteristics such as demographic characteristics and travel attributes, underlying traits such as personality types and attitudes also have significant impacts on SWB (DeNeve and Cooper 1998; Diener et al. 2003). Unlike manifest/external characteristics, personalities and attitudes are latent, individual measures that can have wide-ranging impacts on a broad array of responses such as dominance, sociability, emotional stability, and trust (Ajzen 2005). Personality traits may influence SWB directly, with certain traits (e.g., extraversion, neuroticism) resulting in different experiences of positive/negative affect, or influence SWB indirectly, by guiding people's behaviors and the resulting outcomes (Soto 2015). Attitudes are latent constructs that represent a person's perspective on specific aspects of life (Ajzen 2005) such as education, environment, and transportation, to name a few. Life satisfaction is also an attitudinal construct, which reflects one's perspective on/assessment of life (Heller et al. 2006).

Thus, latent factors such as personality orientations and attitudes can help researchers to understand and explain SWB using internal characteristics that can potentially represent motivations and values. Numerous researchers have included personalities and attitudes in their models to better explain SWB. For example, Helliwell and Putnam (2004) show that those who believe themselves to live among trustworthy people report higher SWB. McCarthy and Habib (2018) find that community-mindedness positively influences SWB, while people who take pride in owning a car have higher SWB. Thus, we see that personalities and attitudes can aid in better understanding different levels of SWB among individuals.

\section{Context-control variables}

Empirical research by Lucas and Donnellan (2007) has shown that one third of the variance in life satisfaction exhibits complete stability over time, with another one third of the variance showing moderate stability, and the remaining instability attributable to contextual circumstances. 
Many longitudinal studies have examined SWB trends over time. For example, Blanchflower and Oswald (2004) found that happiness declined through the last quarter of the twentieth century in the U.S.; however, they found almost no change in Great Britain during the same time period. More recently, Ortiz-Ospina and Roser (2018) analyzed SWB trends from the World Value Survey (WVS) and found that 49 of 69 countries have positive happiness trends over time (1984-2014). Other findings also show that SWB differs across regions. For example, Morrison and Weckroth (2018) found that metropolitan inhabitants of Finland had significantly lower average life satisfaction than their non-metropolitan counterparts. In a more nuanced report, Requena (2016) concludes that in wealthier countries, those living in rural areas have higher levels of SWB relative to those living in urbanized centers, while city dwellers in less prosperous countries have higher SWB relative to their counterparts in lower-density regions.

To study the contextual effects on SWB in a more systematic manner, many researchers include specific context-control variables in their models. Such variables might include GDP (Diener et al. 2010), unemployment rate (Di Tella et al. 2001; Ochsen 2011), social inequality (Kelley and Evans 2017), democratic governance (Frey and Stutzer 2000), geographic characteristics (e.g., sunshine hours) (Oswald and Wu 2010), culture (Oishi 2006), etc.

For longitudinal across-region SWB surveys, the best case is to use consistently designed surveys such as the WVS. However, such resources will commonly not exist if researchers want to study SWB with specific domain variables. Given that we used a fused dataset developed from five travel-behavior oriented surveys, there were differences in sampling methods across component surveys. Based on literature showing that stratified samples from online panels are not representative of the entire population regarding demographic characteristics, attitudes, and behaviors (Blasius and Brandt 2010; Fan and Yan 2010; Szolnoki and Hoffmann 2013), we introduce a context variable to control for varying sample sources.

To summarize, in this literature review section, we introduced SWB as a conceptual construct and discussed prominent measurement philosophies, providing support for our use of a single-item measure for life satisfaction. We then drew from the literature to examine the effects of demographic characteristics, travel-related attributes, personality/attitudinal constructs, and contextual variables on SWB, providing a foundation to better understand the models developed for this analysis.

\section{Overview of data}

\section{Cross-sectional surveys}

This study utilizes a fused dataset of five California-based, transport-oriented crosssectional surveys covering a 27-year period from 1992 to 2018. These five surveys were selected for this specific analysis as they all contained the same life satisfaction question, which is the key dependent variable in this study, and were implemented within California, creating a degree of homogeneity of geographic context. One co-author of this paper was responsible for or integrally involved with the survey design, development, and implementation processes across all surveys considered for this data fusion process, while other co-authors were responsible for or integrally involved with one or more of them. Table 1 provides an overview of key characteristics of the surveys; here, we discuss these 


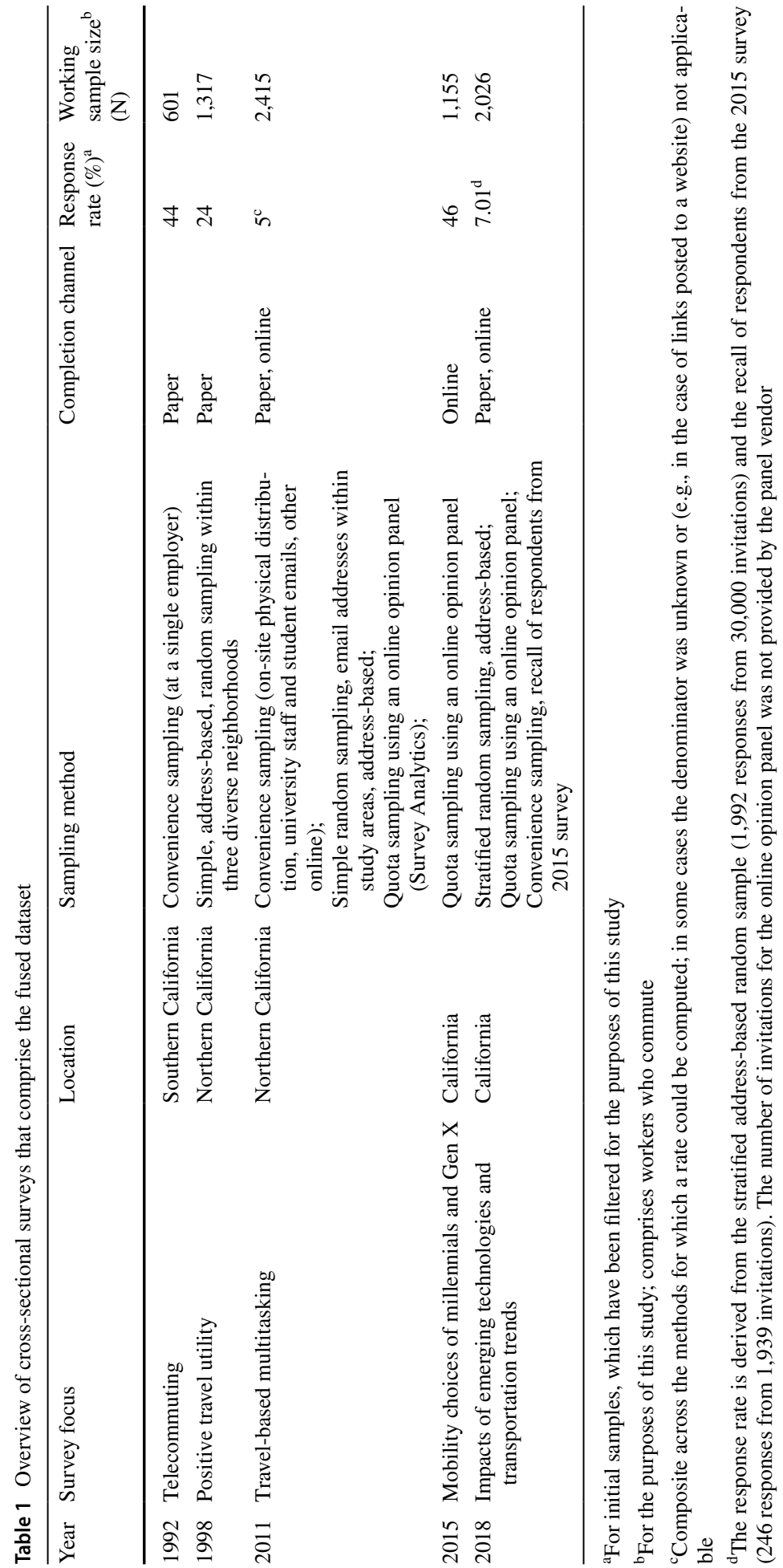


characteristics, providing additional context regarding the original goals and distinctive features of each survey.

The earliest survey, conducted in 1992, was deployed with the overarching goal of studying telecommuting, then defined as the concept of working from home or a location closer to home, thus eliminating the need to travel to and from work (i.e., commuting). Telecommuting was hailed as an exciting game-changer in the early 1990s, and seen as a strategy for reducing congestion and emissions. The survey was deployed to six of twenty-seven departments in the City of San Diego, California, and all regular employees within those departments were surveyed. This convenience sampling method was not used in any of the remaining five surveys, and resulted in a very high response rate of 44\% (Mokhtarian and Salomon 1996).

The next survey in the series was conducted six years later in 1998, and was deployed with the intention of measuring the existence and impact of positive attitudes toward travel itself (particularly local daily travel), in contrast to the conventional view of travel as a disutility, undertaken purely for instrumental reasons of reaching a desired destination. This survey used address-based simple random sampling across three judgmentally-selected San Francisco Bay Area neighborhoods with diverse landuse, travel, and demographic patterns; the overall survey had a response rate of $24 \%$ (Curry 2000). Although surveys involving the same investigator that were conducted in 2003, 2006, and 2009 were also considered, the next one with enough commonalities to be included in the fused dataset of this current study occurred in 2011.

The 2011 survey focused on multitasking during commute travel (i.e., attitudes and behaviors related to travel-based multitasking). This survey used several sampling methods (see Table 1) with the goal of obtaining sizable (rather than representative) shares of all pertinent means of travel (modes). Survey distribution channels included physical distribution on public transit, employee/student email lists from organizations including a large university, a large email list of Sacramento-area commuters interested in alternatives to solo driving, email and mailing addresses purchased from commercial marketing companies, and survey links posted on transportation agency and corporation websites. Where measurable, response rates across the various sampling channels varied from $0.23 \%$ (for the email addresses purchased from a marketing corporation) to $18.2 \%$ (for the physical distribution on public transit; Neufeld and Mokhtarian 2012).

The next survey included in the dataset was conducted in 2015, and focused on the mobility choices of Generation Y (Millennials, born in 1981-1997) and Generation $\mathrm{X}$ (born in 1965-1980). This study used an online opinion panel, and applied a quota sampling approach using targets for gender, age, race, ethnicity, household income, and presence of children in an effort to ensure diverse representation of the population in California. This sampling method resulted in a high response rate of $46.3 \%$, which is not surprising as the invitations for this survey were sent to members of an online opinion panel. These individuals had previously self-selected into the panel, and were available to complete surveys in exchange for incentives in the form of reward points, gift cards or airline miles (Circella et al. 2016).

The final survey included in the fused dataset was fielded in 2018, which is the second wave of the 2015 survey. The 2018 survey aimed to study the impacts of emerging technologies (e.g., ride-hailing services, autonomous vehicles) and transportation trends through a unique longitudinal approach. Specifically, part of the sampling frame of the 2018 survey came from the 2015 survey respondents. Among the re-contacted respondents, 246 people completed the 2018 survey. The rest of the 2018 survey 
respondents were recruited from two sources: a stratified, address-based random sample, and a quota sample from an online opinion panel (Circella et al. 2019, see Table 1 for the response rate).

\section{Data fusion framework}

The basic process we undertook to fuse the surveys discussed in the preceding section can perhaps serve as a framework for others interested in such an approach. We first developed a question "inventory" spreadsheet, which included all survey questions and possible response choices across the surveys. Next, we categorized the survey questions using a four-level hierarchical classification system, the first level of which specified a general, broad category for each survey question. General categories included attitudes, sociodemographic characteristics, travel attributes, land use characteristics, and specific survey focused questions. Next, we categorized each survey question according to its specific topic; for example, general values, environment, lifestyle, travel, time use, work, etc. The remaining categories in the hierarchy simply specified in greater detail what aspect of the topics are covered in each question. This hierarchical labeling system then allowed us to group questions that conveyed essentially identical meanings based on content and possible answer choices, while allowing for minor wording and formatting differences. In the next section, we provide descriptive statistics for the dependent variable in this study (i.e., satisfaction with life), as well as the common explanatory variables used across the surveys, and detail some of the adjustments that were made to facilitate the data fusion process.

\section{Variables used in the study}

For the purposes of this analysis, we restrict our sample to commuters only (i.e., workers who travel to and from work), to increase the homogeneity of context across all survey datasets. Furthermore, by filtering out the non-workers, we are able to retain more travelrelated (specifically, commute-related) variables in the model. After removing inattentive and incomplete cases, the final fused dataset comprises 7,514 valid cases for use in this study (see Table 1 for sample size by survey). Each of the five surveys obtained life satisfaction ratings by asking respondents to rate the statement "I am generally satisfied with my life" using a five-point Likert-type response scale ranging from strongly disagree (1) to strongly agree (5).

Figure 1a presents the life satisfaction rating distribution for each survey, and illustrates that there is an increasing trend over the years with the exception of the survey conducted in 2015-which only used an online opinion panel to sample respondents, and also had the narrowest age range. This observation prompted us to compare the group of all opinion panel respondents (part of the 2011 and 2018 sample [Fig. 1b], and all of the 2015 sample) to everyone else, and we found that there was a significantly lower mean life satisfaction $(t=9.326$, d.f. $=5450.8, p<0.001)$ for the opinion panel group. However, because recruitment via an opinion panel (particularly in 2015; see the "Cross-sectional surveys" section and Table 1) is somewhat confounded with belonging to age groups whose SWB might be expected to be lower than average (Millennials having entered the workforce during a major recession, and Gen Xers being near the bottom of the U-shaped relationship of age to SWB as described in the "Demographic characteristics" section), we revisit this effect in the "Model estimation and analysis" section, using generalized ordered probit models 


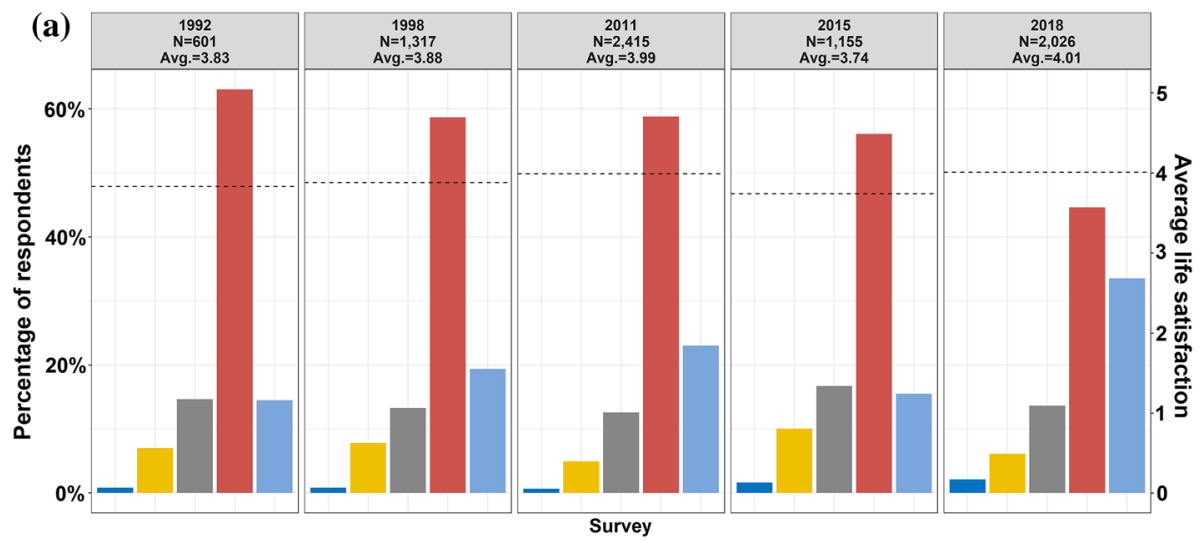

Statement: I am generally satisfied with my life.

$\square$ 1-Strongly disagree $\square$ 2-Disagree $\square$ 3-Neutral $\square$ 4-Agree $\square$ 5-Strongly agree

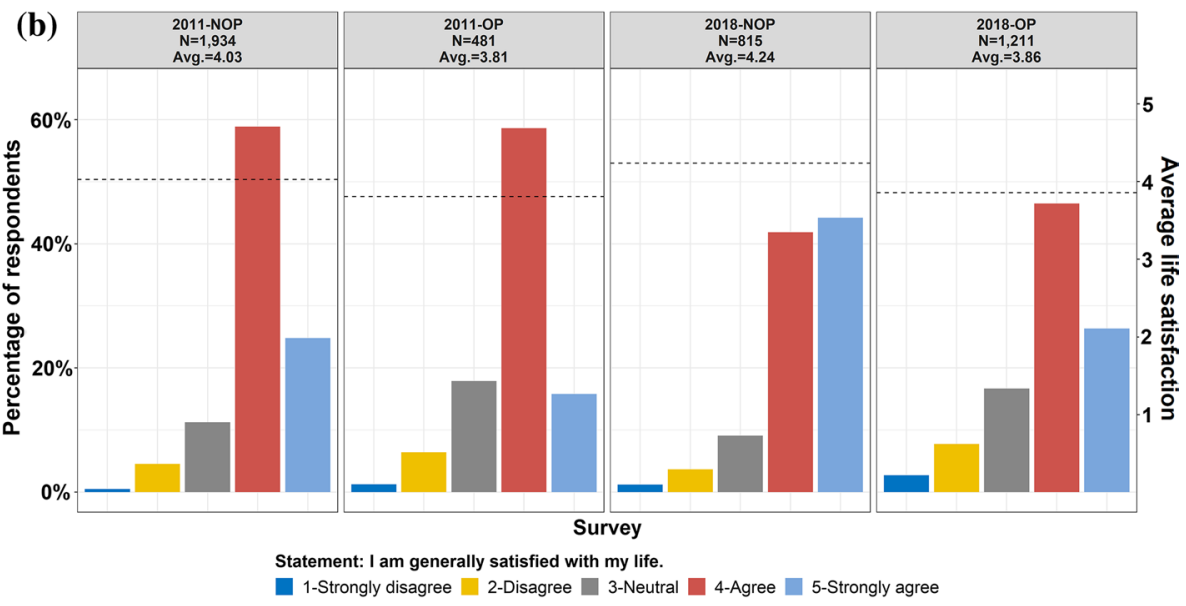

Fig. 1 Distribution of self-reported ratings of life satisfaction by survey. Notes: For the 2011 and 2018 surveys, "OP" represents survey respondents from an online opinion panel, whereas "NOP" represents the rest of the survey respondents. The 1992 and 1998 surveys did not recruit respondents from online opinion panels, while the 2015 survey respondents are all from an online opinion panel

that control for age and other variables. The overall mean for the fused dataset was 3.92 (out of 5).

Figure 2 presents the life satisfaction rating distribution by region. We see that among the three California regions, Northern Californians have the highest average life satisfaction, followed by respondents from "other" California regions and Southern Californians.

Table 2 summarizes descriptive statistics for the explanatory variables used in the models, which are presented in the "Model estimation and analysis". Prior to executing the models, it was necessary to transform several variables to obtain a consistent scale across surveys. For example, the original five surveys have different household income categories to reflect income distributions at the time of survey implementation. For this modeling effort, we used the mid-point of each income category from the original surveys and converted this to the equivalent purchasing power in June 2018 (the implementation date for the last survey in the fused dataset). To do this, we used the consumer price index (CPI) 


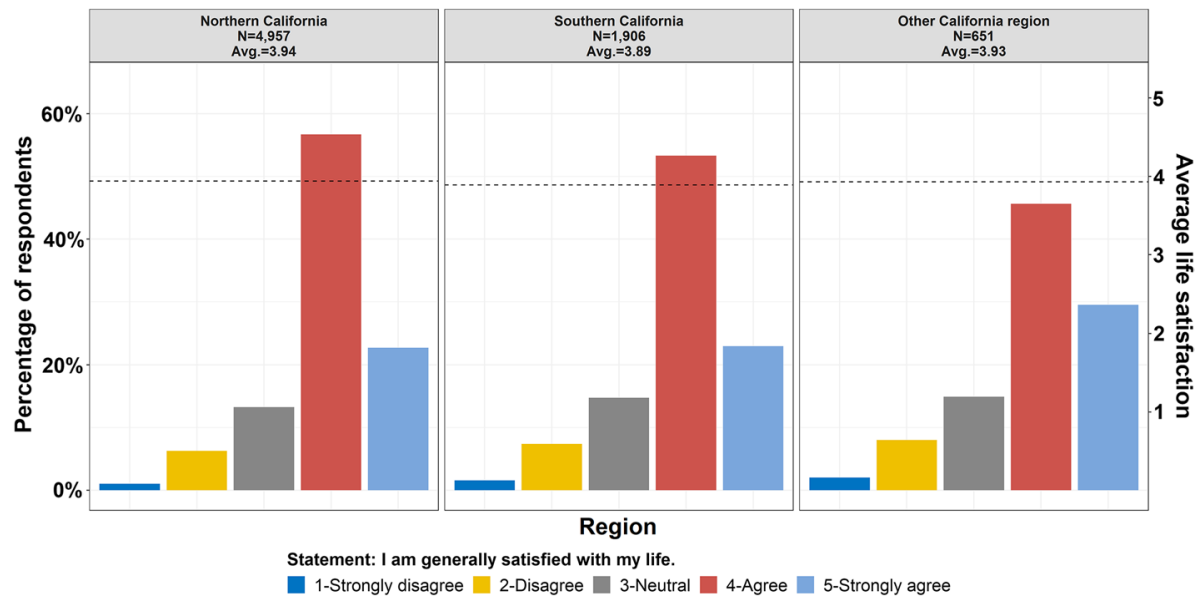

Fig. 2 Distribution of self-reported ratings of life satisfaction by region. Notes: Northern California includes the Sacramento Area Council of Governments (SACOG) and Metropolitan Transportation Commission (MTC - San Francisco Bay Area) regional planning areas. Southern California includes the Southern California Association of Governments (SCAG - Los Angeles) and San Diego Association of Governments (SANDAG) regional planning areas

from the Bureau of Labor Statistics to convert all category midpoints to "2018 dollars", after which we classified the converted household incomes into the six income categories used in the 2018 survey, in keeping with the need for consistency across surveys. The income distribution after conversion is shown in Table 2. This is detailed here as an example of the types of consistency conversions necessary when fusing cross-sectional surveys across time.

To further simplify model development, we treat income and education as continuous variables in the models. The original age statistics for each survey are listed in Table 2. In the modeling portion of this paper, we use mean-centered age to provide more natural interpretations of the impact of age (by considering changes from the mean age rather than changes from 0 years old) and to introduce a quadratic term into the models (Enders 2016). Table 3 shows the slightly differing statements representing the five attitudinal variables retained in the fused dataset; respondents were asked to rate the statements using a five-point Likert-type response scale. We also note that similarly modest differences in wording exist not only in the attitudinal statements, but also in survey questions that obtain demographic and travel-related characteristics. We acknowledge that the subtle differences in wording between the surveys may influence respondents' final responses, but note that such differences will be common consequences of fusing disparate datasets. We also exercised what we believe to be conservative judgments about the extent of differences that we considered acceptable; i.e., we eliminated questions/statements that we considered likely to result in rating differences across surveys. As a result, all retained variables are believed to convey the same meaning to respondents across surveys, although slight variations in wording are still present.

Overall, the full sample consists of slightly more females than males (54\% vs. $46 \%$ ). More than $60 \%$ of respondents hold a bachelor's degree or higher. Fewer than $20 \%$ of respondents live alone, and most of them (97\%) hold a driver's license. About two-thirds of the survey respondents come from Northern California (66\%), compared to 25\% Southern Californians and 9\% Californians from other regions. 


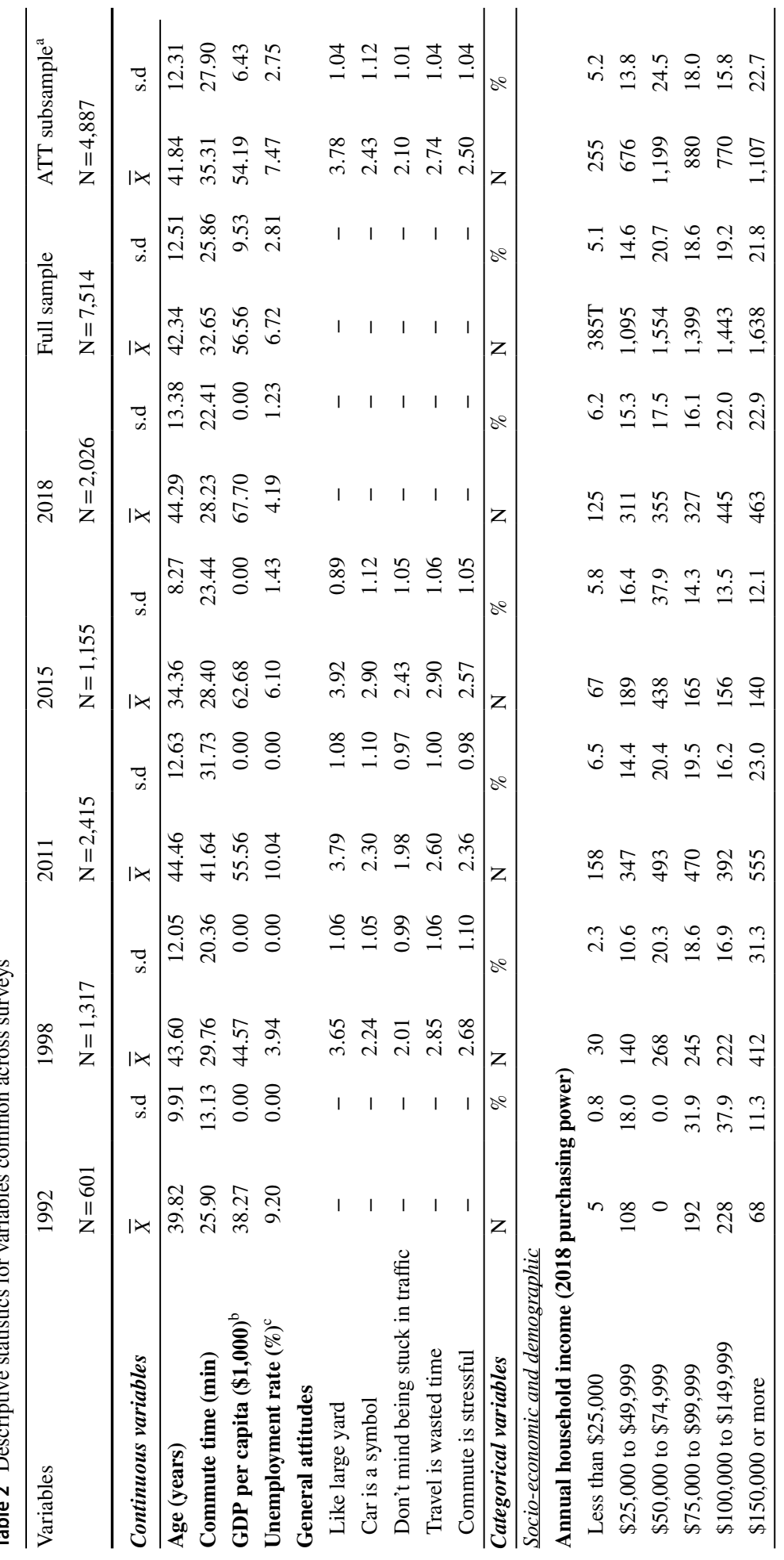




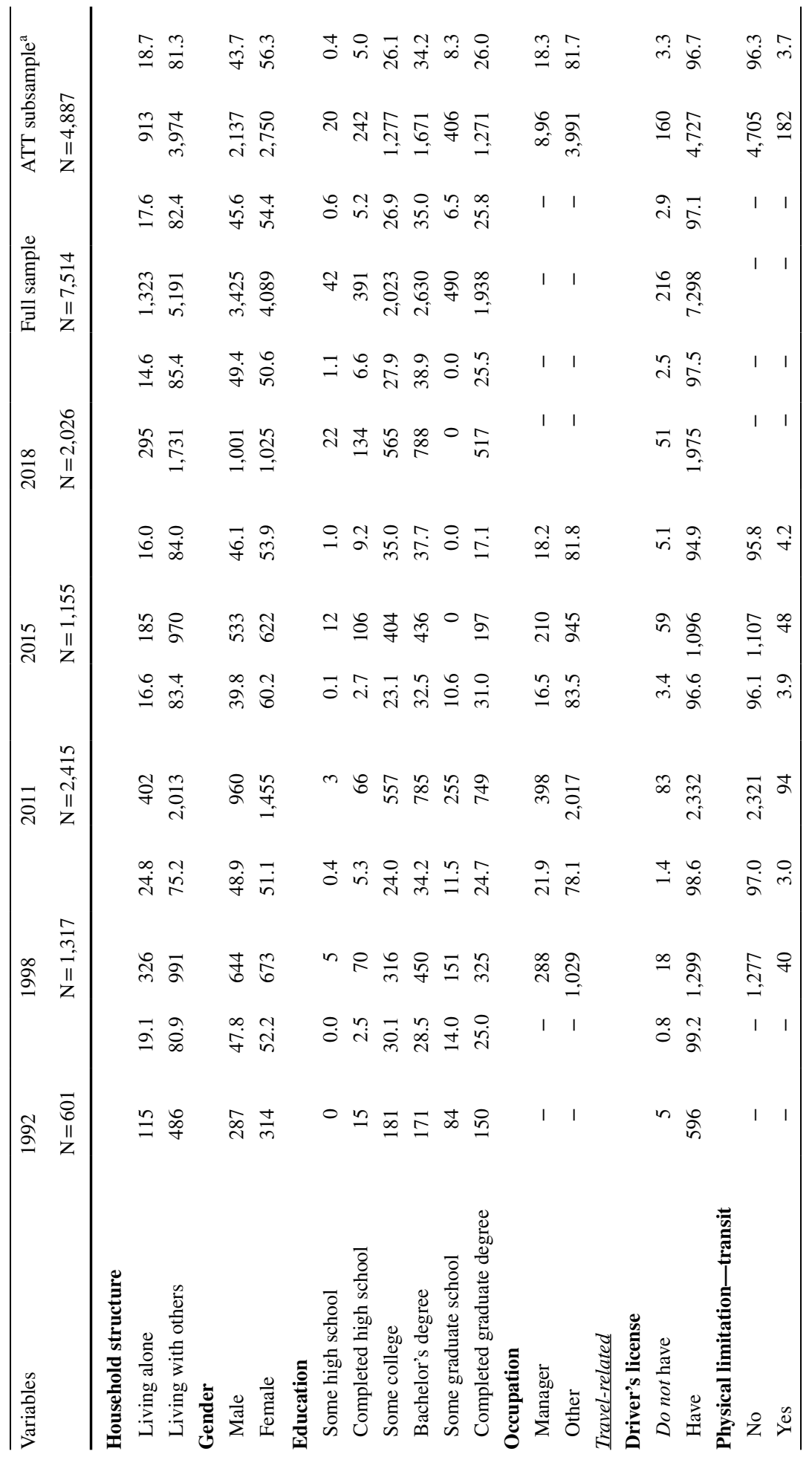




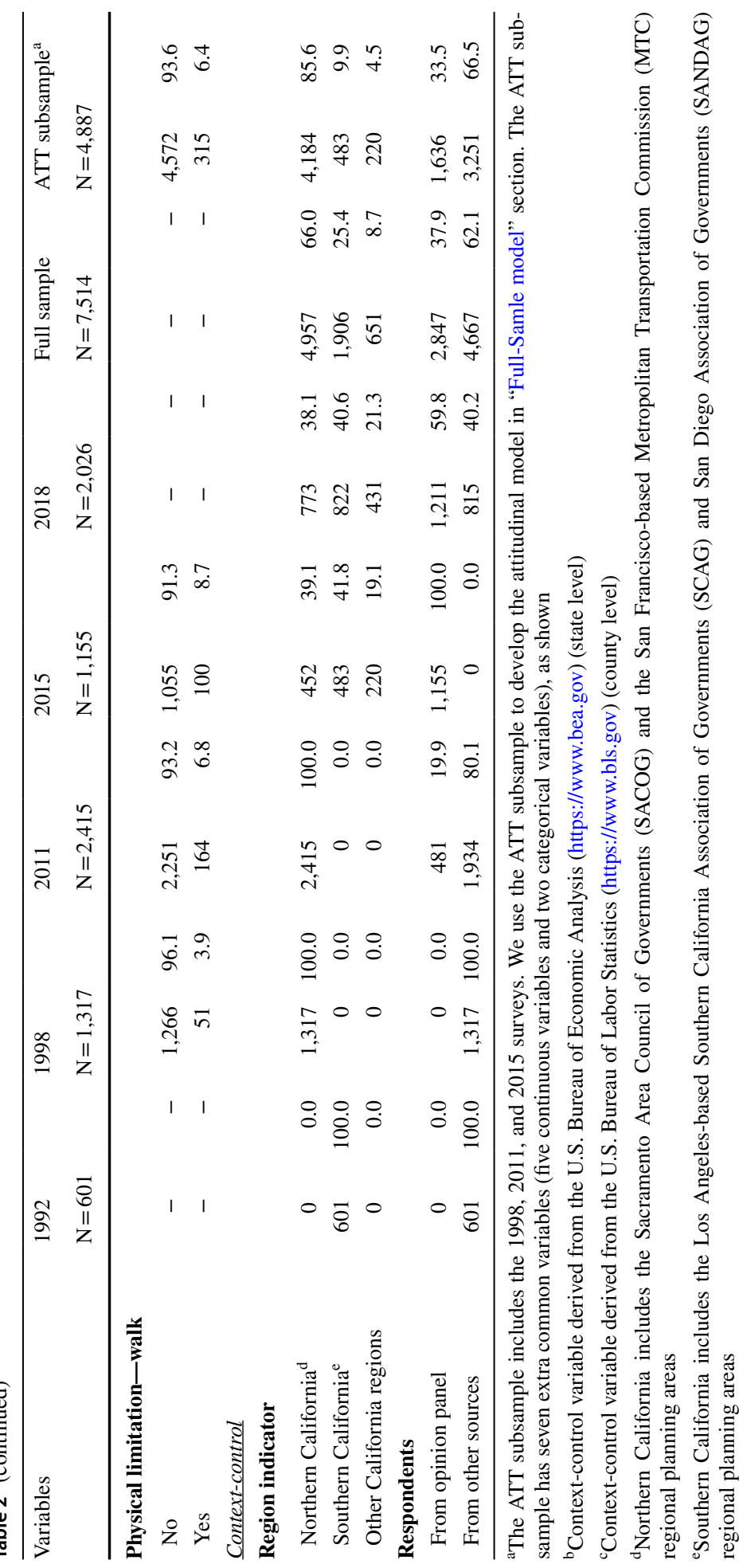




\section{Model estimation and analysis}

Two generalized ordered logit models for satisfaction with life are developed and presented here; we note that the first of these models uses the fused dataset across all five surveys, while the second model uses a reduced version of the fused dataset that includes three of the five surveys (1998, 2011, and 2015). The model utilizing all five surveys is described as the full-sample model. The full-sample model includes a geographically and chronologically widespread sample, with which we focus on the examination of context variables such as GDP, unemployment rate, and sampling method. The reduced model is described as the attitudinal model since it allows an examination of attitudinal variables. The full-sample model maximizes the sample size, while the second model enlarges the set of common variables to include five transport-related attitudinal variables, at the cost of losing two of the five surveys (Table 3). Besides these variables of particular interest (i.e., the contextual and attitudinal variables), we retain demographic characteristics and other travel-related variables in both models.

\section{Generalized ordered logit model}

In this study, satisfaction with life is measured using a five-point Likert-type response scale from "strongly disagree" to "strongly agree". As such, ordinal logit (OL; ordered logit) models would serve this analysis well. However, the dataset used in this analysis violates the parallel lines assumption of OL models, a violation that frequently occurs in practice (Williams 2006). The parallel lines assumption requires corresponding coefficients (with the exception of the intercept) to be identical across different levels of the dependent variable.

Therefore, we use a less restrictive form of OL, the generalized ordered logit (GOL) model. GOL models relax the parallel lines restriction on the explanatory variables that violate this assumption, while keeping coefficients for the remaining explanatory variables in a parsimonious form (Williams 2016). We also considered using the multinomial logit (MNL) model, since MNL does not impose the parallel lines assumption across explanatory variables; however, MNL does not take into account the ordinal nature of the dependent variable. Furthermore, in empirical practice, the MNL specification would result in substantially more model coefficients than GOL. As a result, to balance parsimony, conceptual fidelity, and interpretability, we selected GOL models for use in the analysis presented here. The gologit2 specification in Stata/IC15.1 was used for model development (Williams 2006).

The GOL model specification can be written as follows:

$$
P\left(Y_{i}>j\right)=g\left(\alpha_{j}, \boldsymbol{X}_{i} \boldsymbol{\beta}_{j}\right)=\frac{\exp \left(\alpha_{j}+\boldsymbol{X}_{i} \boldsymbol{\beta}_{j}\right)}{1+\left\{\exp \left(\alpha_{j}+\boldsymbol{X}_{i} \boldsymbol{\beta}_{j}\right)\right\}} \quad j=1,2, \ldots, M-1,
$$

where $Y_{i}$ represents the life satisfaction of respondent $i ; \alpha_{j}$ is the constant term associated with response $j ; X_{i}$ is a vector of explanatory variables; $\beta_{j}$ is the corresponding vector of coefficients associated with response $j$ (some, but not necessarily all, elements of which may be equal across some values of $j$ ); and $M$ is the number of life satisfaction categories, which is five in this study; $\alpha_{j}+X_{i} \beta_{j}$ can be interpreted as the observed propensity for life satisfaction to be greater than response $j$. GOL models are different from OL models in that 
Table 3 Attitudinal variables common across surveys

\begin{tabular}{|c|c|c|}
\hline Attitudinal variable & Survey & Survey statements \\
\hline \multirow[t]{3}{*}{ Like large yard } & 1998 & I like to have a large yard at my home. \\
\hline & 2011 & $\begin{array}{l}\text { I like the idea of living somewhere with large yards } \\
\text { and lots of space between homes. }\end{array}$ \\
\hline & 2015 & $\begin{array}{l}\text { I like the idea of living somewhere with large yards } \\
\text { and lots of space between homes. }\end{array}$ \\
\hline \multirow[t]{3}{*}{ Car is a symbol } & 1998 & To me, a car is a status symbol. \\
\hline & 2011 & $\begin{array}{l}\text { I (would) like to own a car that impresses other } \\
\text { people. }\end{array}$ \\
\hline & 2015 & To me, owning a car is a symbol of success. \\
\hline \multirow[t]{3}{*}{ Don't mind being stuck in traffic } & 1998 & Getting stuck in traffic doesn't bother me too much. \\
\hline & 2011 & Getting stuck in traffic doesn't bother me much. \\
\hline & 2015 & Getting stuck in traffic does not bother me that much. \\
\hline \multirow[t]{3}{*}{ Travel is wasted time } & 1998 & Travel time is generally wasted time. \\
\hline & 2011 & Time spent traveling is generally wasted time. \\
\hline & 2015 & The time I spend commuting is generally wasted time. \\
\hline \multirow[t]{3}{*}{ Commute is stressful } & 1998 & My commute is a real hassle. \\
\hline & 2011 & My commute is stressful. \\
\hline & 2015 & My commute is stressful. \\
\hline
\end{tabular}

they allow $\beta_{j}$ to vary with $j$; otherwise, the specifications for GOL and OL models are identical. The probability of each rating category is:

$$
\begin{aligned}
& P\left(Y_{i}=1\right)=1-g\left(\alpha_{1}, \boldsymbol{X}_{i} \boldsymbol{\beta}_{1}\right) \\
& P\left(Y_{i}=j\right)=g\left(\alpha_{j-1}, \boldsymbol{X}_{i} \boldsymbol{\beta}_{j-1}\right)-g\left(\alpha_{j}, \boldsymbol{X}_{i} \boldsymbol{\beta}_{j}\right) \quad j=2, \ldots, M-1 \\
& P\left(Y_{i}=M\right)=g\left(\alpha_{M-1}, \boldsymbol{X}_{i} \boldsymbol{\beta}_{M-1}\right)
\end{aligned}
$$

From this it can be seen that an increase in $\alpha_{1}+\boldsymbol{X}_{i} \boldsymbol{\beta}_{1}$ will unequivocally decrease the probability of the lowest life satisfaction response, and an increase in $\alpha_{M-1}+\boldsymbol{X}_{i} \boldsymbol{\beta}_{M-1}$ will unequivocally increase the probability of the highest response, but the effect of increases in $\alpha_{j}+\boldsymbol{X}_{i} \boldsymbol{\beta}_{j}$ on the middle three responses is ambiguous (Greene 2018). For this reason, we will interpret variables that have consistent effects across life satisfaction levels (i.e. for which the $\beta_{j}$ 's are equal across $j$ ) in terms of increases or decreases in the propensity for life satisfaction, which is unambiguous. For variables that have differing effects across life satisfaction levels (i.e. for which the $\beta_{j}$ 's vary across $j$ ), we will calculate the average marginal effects to illustrate their impact on each life satisfaction response level.

\section{Full-sample model}

The final GOL model developed for this analysis relaxes the parallel lines assumption for household income and the three context-control variables (i.e., GDP per capita, unemployment rate, and the opinion panel indicator), as we found that there are different effects of household income and context-control variables across life satisfaction levels. Table 4 shows the final model results, and indicates that overall, the full-sample model has an acceptable model fit with a $\rho^{2}$ (equally-likely base) of 0.30 . We will interpret the 
explanatory variables found to have significant predictive power for life satisfaction ratings. In addition, Table 5 presents the marginal effects of the explanatory variables whose coefficients have been allowed to relax the parallel line assumption, namely, household income, GDP per capita, unemployment rate, and the opinion panel indicator. Specifically, we present two groups of statistics - actual probability changes and percentage changes in the probability-since each offers meaningful but different insights in view of the unbalanced shares of the five responses. For example, a large incremental change in probability could represent a small percentage change if the baseline share is large, while conversely, a small incremental change could be a large percentage of a small share.

We look first at household level demographic characteristics. As expected, the model shows that increased household income levels tend to increase the propensity for satisfaction with life. Interestingly, the magnitudes of the coefficients decline as life satisfaction levels increase. This suggests that those with lower life satisfaction tend to have greater returns on their satisfaction propensity as their income levels increase. The trend is consistent with the marginal effects (percentage changes in probability). Specifically, a one-level increase in household income results in larger percentage changes in probability for lower life satisfaction levels than for higher life satisfaction levels. The second household-level variable is household structure, which shows that households with more members have an increased propensity to experience greater satisfaction with life relative to those who live alone. Consistent with numerous SWB studies showing the importance of social relationships in general, and close family ties in particular, living with other family members on net brings both practical and emotional support for the burdens of daily life.

Turning now to individual level demographic characteristics, we see that age has a U-shaped relationship with life satisfaction propensity. This indicates that individuals' life satisfaction tends to have a declining trend during their early life stages, with the lowest life satisfaction occurring around the age of 44, on average. After this turning point, people have a greater tendency to be satisfied with their lives. The trend, which is consistent with studies in the literature (Beutel et al. 2010), is conceptually intuitive, as we can conceive that those in the middle-aged portion of life may have a greater number of stressors - career building, marriages, children, ailing parents - that may result in anxiety and decreased life satisfaction (hence the stereotypical mid-life crisis, e.g., Rosenberg et al. (1999). Figure 3 intuitively illustrates the average changes in the probabilities of the five response levels as age varies from 18 to 93. The probability of strongly agreeing with the life satisfaction statement forms a U-shaped curve across adulthood. In contrast, the probabilities of the other responses do not form such curves due to the restriction that the probabilities of the five response levels sum to one. Still, the figure indicates that people in middle age have the lowest propensity to be highly satisfied with their life and the highest propensity to be less satisfied. In terms of gender, the model indicates that, in general, females tend to have a higher propensity for life satisfaction than males (Welsch and Kuehling 2017). We see that individuals with higher levels of education tend toward greater life satisfaction. Regarding occupation, we see that those in managerial positions have an increased propensity to be more satisfied with their life relative to those in other occupations.

Regarding transport attributes, we see that increased commute time tends to have a negative effect on life satisfaction. Commuting is a recurring event, often conducted under time pressure and in less-than-pleasant circumstances, which occupies much of an individual's "travel budget" and serves as a spatio-temporal anchor for many other activities. In the U.S., the vast majority of commuting is performed by driving an automobile, and especially for drivers but also for many others, commute time cannot be 
Table 4 Full-sample models of life satisfaction

\begin{tabular}{|c|c|c|c|c|}
\hline \multirow[t]{2}{*}{ Variable } & \multicolumn{2}{|c|}{ Generalized ordered logit } & \multicolumn{2}{|c|}{$\begin{array}{l}\text { Generalized ordered logit without } \\
\text { contextual variables }\end{array}$} \\
\hline & Coefficient & z-value & Coefficient & $\mathrm{z}$-value \\
\hline \multicolumn{5}{|l|}{ Socioeconomic and demographic } \\
\hline Household income (SD | D) & $0.359 * * *$ & 4.71 & $0.402^{* * *}$ & 5.35 \\
\hline Household income (D | N) & $0.326^{* * *}$ & 10.44 & $0.318^{* * *}$ & 10.44 \\
\hline Household income $(\mathrm{N} \mid \mathrm{A})$ & $0.273 * * *$ & 12.84 & $0.268^{* * *}$ & 12.90 \\
\hline Household income (A I SA) & $0.151^{* * *}$ & 7.28 & $0.150^{* * *}$ & 7.39 \\
\hline Living with others & $0.223 * * *$ & 3.64 & $0.277^{*} * *$ & 4.60 \\
\hline Age (mean-centered) & -0.00210 & -1.06 & $0.00386^{* *}$ & 2.03 \\
\hline Age (mean-centered) squared & $0.000763 * * *$ & 5.84 & $0.000944 * * *$ & 7.31 \\
\hline Female & $0.178 * * *$ & 3.91 & $0.182 * * *$ & 4.02 \\
\hline Education & $0.0743 * * *$ & 3.83 & $0.0933^{* * *}$ & 4.90 \\
\hline \multicolumn{5}{|l|}{ Travel-related } \\
\hline Have a driver's license & $0.358 * * *$ & 2.67 & $0.377 * * *$ & 2.82 \\
\hline Commute time & $-0.00416^{* * *}$ & -4.61 & $-0.00294 * * *$ & -3.35 \\
\hline \multicolumn{5}{|l|}{ Context-control } \\
\hline GDP per capita (SD | D) & -0.0153 & -0.97 & - & - \\
\hline GDP per capita (D | N) & $0.0215^{* * *}$ & 3.51 & - & - \\
\hline GDP per capita ( $\mathrm{N} \mid \mathrm{A})$ & $0.0199 * * *$ & 4.99 & - & - \\
\hline GDP per capita (A I SA) & $0.0487 * * *$ & 13.24 & - & - \\
\hline Unemployment rate (SD | D) & $10.548 * *$ & 2.39 & - & - \\
\hline Unemployment rate (D |N) & $6.922 * * *$ & 4.17 & - & - \\
\hline Unemployment rate $(\mathrm{N} \mid \mathrm{A})$ & $3.948 * * *$ & 3.61 & - & - \\
\hline Unemployment rate (A ISA) & -1.710 & -1.16 & - & - \\
\hline From opinion panel (SD | D) & -0.448 & -1.64 & - & - \\
\hline From opinion panel (D | N) & $-0.525 * * *$ & -4.41 & - & - \\
\hline From opinion panel (N|A) & $-0.559 * * *$ & -7.23 & - & - \\
\hline From opinion panel (A I SA) & $-0.726 * * *$ & -10.08 & - & - \\
\hline \multicolumn{5}{|l|}{ Thresholds } \\
\hline Threshold 1 (SD | D) & $2.668 * * *$ & 2.59 & $1.873 * * *$ & 6.50 \\
\hline Threshold $2(\mathrm{D} \mid \mathrm{N})$ & $-1.081 * * *$ & -2.72 & 0.192 & 1.07 \\
\hline Threshold 3 (N|A) & $-1.820 * * *$ & -6.39 & $-0.849 * * *$ & -5.12 \\
\hline Threshold 4 (A | SA) & $-5.152 * * *$ & -17.85 & $-2.960 * * *$ & -16.97 \\
\hline \multicolumn{5}{|l|}{ Model summary } \\
\hline Number of cases & & 7,514 & & 7,514 \\
\hline Log-likelihood (0) & & $-12,093.32$ & & $-12,093.32$ \\
\hline Log-likelihood (thresholds) & & $-8,853.27$ & & $-8,853.27$ \\
\hline Log-likelihood $(\widehat{\beta})$ & & $-8,494.77$ & & $-8,632.21$ \\
\hline$\rho^{2}$ (equally-likely base) & & 0.2976 & & 0.2862 \\
\hline$\rho^{2}$ (thresholds-only base) & & 0.0405 & & 0.0250 \\
\hline
\end{tabular}

For this sample, the shares of each response are strongly disagree (SD): $1.25 \%$, disagree (D): $6.71 \%$, neutral (N): $13.79 \%$, agree (A): $54.88 \%$, and strongly agree (SA): $23.37 \%$

$* * *$ Coefficient is statistically significant at the 0.01 level

$* *$ Coefficient is statistically significant at the 0.05 level

*Coefficient is statistically significant at the 0.1 level 
used as productively as may be desired (Shaw et al. 2019). For these reasons, among others, it is not surprising that longer commutes have a deleterious effect on travel wellbeing (Smith 2017) and overall life satisfaction (Hilbrecht et al. 2014).

On the other hand, we also see that having a driver's license has a positive effect on life satisfaction propensity. As an instrument of motility (De Vos et al. 2013), license possession can increase one's mobility by providing travel flexibility and an increased radius of potential travel. As witnessed by the literature on the mobility of the elderly, simply being able to drive can intuitively increase overall life satisfaction (Banister and Bowling 2004). Thus, we see that commuting specifically has an opposing effect to that of travel freedom generally - probably because of the lack of freedom found in much commuting.

The three contextual variables-GDP per capita, unemployment rate, and sampling method-have differing effects across life satisfaction levels. In general, people from regions with a higher GDP per capita are more likely to feel satisfied with life. Also, GDP per capita has the most substantial effects (i.e., the largest positive coefficient) on people who have a high propensity to feel satisfied with life. However, based on the marginal effects shown in Table 5, a one-unit $(\$ 1,000)$ increase in GDP per capita also results in a slight increase in the probability of the lowest life satisfaction level. Interestingly, the unemployment rate positively associates with life satisfaction, i.e., a higher unemployment rate is related to higher life satisfaction. One potential explanation resides in recalling the target group of this study, i.e., employed people. Considering their unemployed peers, people who do not lose their jobs when the unemployment rate is high may be more appreciative of their life than at other times. The marginal effects in Table 5 further show that a one-percentage-point increase in the unemployment rate will result in a probability increase of the medium-high level of life satisfaction ("Agree") and probability reductions for the other life satisfaction levels.

In addition to the specific context-control variables of GDP per capita and unemployment rate, we considered including context-control indicators to capture the average impacts of certain unobserved contextual factors. First, we tested using region and year indicators as substitutes for the specific contextual variables in the full-sample model. See Table 7 in the Appendix for the model results. Compared to using specific contextual variables, the interpretability of the context-control indicators is relatively weak. For example, in the context indicator model, we see that life satisfaction has an increasing trend over the years, ${ }^{2}$ while people from southern and other California regions have a higher life satisfaction than people from northern California. However, the sources of, or reasons for, these life satisfaction differences are unknown. Further, the fit of the context indicator model is lower than that of the model using specific contextual variables. We also tested including the context-control indicators together with the specific context-control variables; however,

\footnotetext{
2 This result diverges from the literature. For example, Blanchflower and Oswald (2004) report that life satisfaction has been declining for the last quarter of the twentieth century. This may be attributable to a host of reasons. On the one hand, the study reported in this paper captures more recent time periods that are not reported in the literature, i.e., through 2018. On the other hand, differences in sampling method, survey design, and other factors may be contributing to the differences in trends as well. It is also pertinent to note that given the trend of declining survey response rates around the world (National Research Council 2013; Morton, Cahill and Hartge 2005), the sample of respondents who are willing to spend time to complete the fairly lengthy, detailed surveys analyzed here may be becoming increasingly less representative with each new cross-section, potentially biased toward having less time pressure, a greater sense of social responsibility, and/or more positive life attitudes.
} 
Table 5 Average marginal effects of variables with relaxed parallel line assumption in the full-sample model of life satisfaction

\begin{tabular}{|c|c|c|c|c|c|c|}
\hline & & Strongly disagree & Disagree & Neutral & Agree & Strongly agree \\
\hline Baseline shares & & 0.0125 & 0.0671 & 0.1379 & 0.5488 & 0.2337 \\
\hline \multirow[t]{2}{*}{$\begin{array}{l}\text { Household } \\
\text { income }\end{array}$} & $\begin{array}{c}\text { Probability } \\
\text { change }^{\mathrm{a}}\end{array}$ & -0.00438 & -0.0187 & -0.0209 & 0.0184 & 0.0256 \\
\hline & $\begin{array}{l}\% \text { change in } \\
\text { probability }^{\mathrm{b}}\end{array}$ & $-35 \%$ & $-29 \%$ & $-17 \%$ & $3 \%$ & $12 \%$ \\
\hline \multirow[t]{2}{*}{ GDP per capita } & $\begin{array}{c}\text { Probability } \\
\text { change }^{\mathrm{a}}\end{array}$ & 0.000187 & -0.00171 & -0.00168 & -0.00502 & 0.00823 \\
\hline & $\begin{array}{l}\% \text { change in } \\
\text { probability }^{\mathrm{b}}\end{array}$ & $1.5 \%$ & $-2.6 \%$ & $-1.3 \%$ & $-0.9 \%$ & $3.7 \%$ \\
\hline \multirow[t]{2}{*}{$\begin{array}{l}\text { Unemployment } \\
\text { rate }\end{array}$} & $\begin{array}{c}\text { Probability } \\
\text { change }^{\mathrm{a}}\end{array}$ & -0.129 & -0.362 & -0.145 & 0.925 & -0.289 \\
\hline & $\begin{array}{l}\% \text { change in } \\
\text { probability }^{\mathrm{b}}\end{array}$ & $-1042 \%$ & $-566 \%$ & $-133 \%$ & $174 \%$ & $-131 \%$ \\
\hline \multirow[t]{2}{*}{$\begin{array}{l}\text { From opinion } \\
\text { panel }\end{array}$} & $\begin{array}{c}\text { Probability } \\
\text { change }^{c}\end{array}$ & 0.00539 & 0.0332 & 0.0547 & 0.0249 & -0.118 \\
\hline & $\begin{array}{l}\% \text { change in } \\
\text { probability }^{\mathrm{d}}\end{array}$ & $44 \%$ & $49 \%$ & $40 \%$ & $5 \%$ & $-56 \%$ \\
\hline
\end{tabular}

${ }^{\text {a }}$ The probability changes of each response level from a one-unit increase in the explanatory variable. For each explanatory variable, probability changes across the five response levels sum to one

${ }^{b}$ The proportional changes in the probability of each response level given a one-unit increase in the explanatory variable

${ }^{\mathrm{c}}$ The probability changes associated with belonging to an opinion panel, for each response level. The probability changes across the five response levels sum to one

${ }^{\mathrm{d}}$ The proportional changes in probability associated with belonging to an opinion panel, for each response level

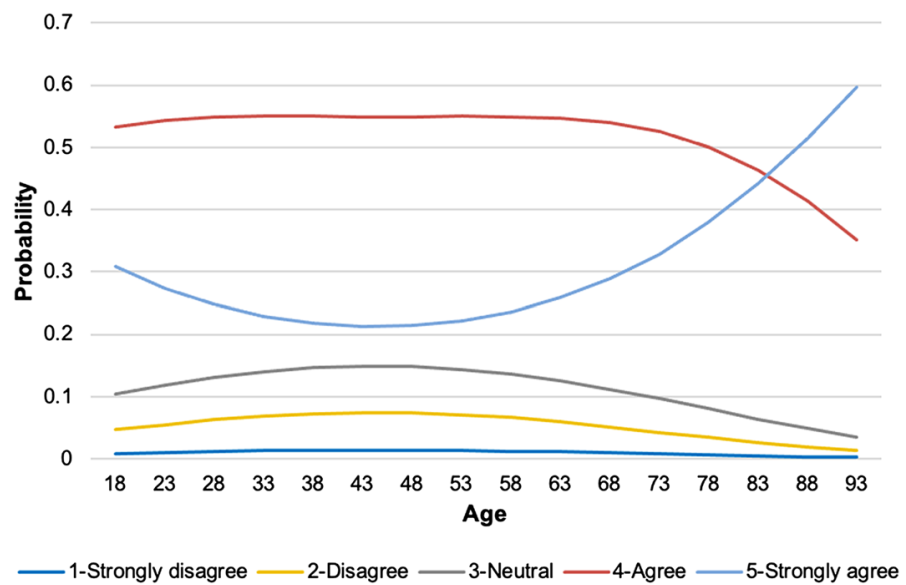

Fig. 3 Average changes in the probabilities of different life satisfaction response levels with age 
the two indicators were insignificant when GDP per capita and the unemployment rate were also in the model.

Regarding the sampling method, online opinion panel respondents tend to have lower life satisfaction propensities relative to respondents recruited using the other sampling methods (mainly address-based sampling). One possible explanation is that the two groups of people have different purposes for survey participation. The online panel respondents are people who previously registered at some websites for survey participation with rewards, while the other sampling methods (mainly address-based sampling) recruit essentially volunteer respondents (even though most of the surveys provided some small incentives). With this in mind, we can see that the online panel respondents may have more financial pressure and possibly more ennui, while the volunteer respondents are more likely both to be in a benevolent mood when they started the survey, and to have their sense of well-being further improved by the knowledge of being helpful by completing the survey.

To further analyze the effects of contextual variables, we executed a restricted version of the model with contextual variables removed (Table 4). As we can see, coefficients for the remaining variables do not change dramatically, which suggests the model's stability and the independent explanatory power of the two groups of variables. ${ }^{3}$ The likelihood ratio test for the removal of a block of variables decisively rejects the null hypothesis that all the contextual variables are irrelevant $\left(\chi^{2}=274.88\right.$, d.f. $\left.=12, p<0.001\right)$, which indicates the importance of contextual influences in life satisfaction modeling.

\section{Attitudinal model}

As noted, the attitudinal model (Table 6) is developed using a reduced version of the fused dataset, comprising only three surveys (the 1998, 2011, and 2015 surveys), and thus facilitating the inclusion of a larger set of common variables. To be specific, the attitudinal model includes all explanatory variables used in the full-sample model (as shown in Table 4) as well as seven additional variables that encompass travel-related attributes and attitudes. The attitudinal and full-sample models have similar model results (coefficient and significance) for the shared explanatory variables; accordingly, for economy of presentation, we here focus on interpreting the seven new variables.

Two of the seven additional explanatory variables are travel-related attributes that relate to whether respondents have physical conditions or anxieties that limit their use of transit or walking (i.e., Physical limitation-transit and Physical limitation-walk). Results indicate that those with physical limitations have lower life satisfaction propensities, likely due to restricted mobility. Further, the physical limitations may also reflect the presence of health problems that are not directly measured by our surveys, but which conceivably have negative effects on life satisfaction.

The five additional explanatory variables are transport-oriented attitudinal statements, which reflect general values as well. The first statement, "Like large yard," captures a residential preference for living in locations that allow large yards and lots of space between homes. This statement is usually associated with a pro-suburban attitudinal factor in prior works (e.g., Kim et al., 2019). The positive coefficient indicates that people who prefer living in suburban areas have increased propensities to be satisfied with their lives. Not

\footnotetext{
3 To further test the stability of the model, we conducted bootstrap estimations with 200 replications for both the full-sample model and the attitudinal model (see the "Attitudinal model" section). The standard errors and the corresponding z-values are very similar between our one-time estimations (Tables 4 and 6 ) and the bootstrap estimations, additionally corroborating the stability of the coefficients
} 
surprisingly, the attitudinal result is consistent with the behavioral result; for example, Sander (2011) found that those who live in less urban areas have higher levels of happiness. A possible explanation of the positive relationship between pro-suburban attitudes and life satisfaction is that the suburban life is still an aspiration for many Americans, and may therefore be perceived to offer a more satisfactory living environment. The second attitude, "car as a symbol", reflects the respondent's vanity with respect to owning a car. The results show that respondents who regard cars as status symbols tend to be less satisfied with their lives, perhaps because there will always be others with more status, to whom it is disappointing to compare oneself. Similarly, Olivos et al. (2020) have shown that upward social comparisons have negative effects on life satisfaction.

The last three attitudinal statements ("Don't mind being stuck in traffic," "Travel is wasted time," and "Commute is stressful") capture general preferences toward time use, travel liking, and commuting. Those who don't mind being stuck in traffic have increased propensities for life satisfaction, while-consistently - those who see travel as a waste or commuting as stressful have reduced propensities. These are expected results, especially considering that such attitudes may reflect not only a specific affect toward travel, but also an optimistic/pessimistic outlook on life in general. Note that these attitudes substantially reduce the impact of commute time per se: when attitudes are excluded (as in the second model in Table 6), the coefficient of commute time becomes markedly more negative in compensation, which is not surprising. Nevertheless, even controlling for these attitudes, commute time remains strongly significant.

Thus, we see that the inclusion of these five attitudinal statements allowed for the interpretation of life satisfaction from more dimensions (e.g., personality, time use, travel liking). In Table 6, we also present a model identical to the one discussed here, except with the attitudinal variables removed. Similar to the results for the full-sample model, we note that the remaining explanatory variables have relatively stable coefficients after the attitudes are removed, and also that the likelihood ratio test for the removal of a block of variables decisively rejects the null hypothesis that all the attitudinal variables are irrelevant $\left(\chi^{2}=177.06\right.$, d.f. $=5, p<0.001$ ), which indicates the importance of attitudes in life satisfaction modeling.

\section{Discussion}

In this section, we further discuss our research findings and limitations. Firstly, we note that although the life satisfaction models presented have acceptable $\rho^{2} \mathrm{~s}$ using the equally likely benchmark $(0.2976$ and 0.3256$)$, the $\rho^{2}$ fit statistics using the thresholds-only benchmark (0.0405 and 0.0481) appear quite low. However, this is a typical outcome when the distribution of responses is unbalanced across the points on the ordinal scale, as is the case here (see Fig. 1 and the footnote to Table 4), and does not give a fair picture of the model's explanatory power (Mokhtarian 2016). Furthermore, even if using the thresholds-only benchmark, this model fit is consistent with life satisfaction models in the literature. For example, ordered logit/probit models usually have a pseudo- $R^{2}$ less than 0.05 (Blanchflower and Oswald 2004; Nie and Sousa-Poza 2016). Linear regression models usually have $R^{2}$ values around 0.2 (Helliwell and Putnam 2004) and adjusted $R^{2}$ values around 0.05 (Hilbrecht et al. 2014; Nikolaev 2015). It is also notable that many life satisfaction studies do not report model fits, thus precluding the comparison of their overall model performance relative to others in the literature. Low model fits for life satisfaction indicate that there is a sizable range of factors that influence individuals' conscious evaluation of their lives, and at any one time, a typical 
Table 6 Attitudinal models of life satisfaction

\begin{tabular}{|c|c|c|c|c|}
\hline \multirow[t]{2}{*}{ Variable } & \multicolumn{2}{|c|}{ Model specification with attitudes } & \multicolumn{2}{|c|}{$\begin{array}{l}\text { Model specification without } \\
\text { attitudes }\end{array}$} \\
\hline & Coefficient & $\mathrm{z}$-value & Coefficient & $\mathrm{z}$-value \\
\hline \multicolumn{5}{|l|}{ Socioeconomic and demographic } \\
\hline Household income (SD | D) & $0.442 * * *$ & 3.94 & $0.421 * * *$ & 3.76 \\
\hline Household income (D | N) & $0.306 * * *$ & 7.82 & $0.282 * * *$ & 7.26 \\
\hline Household income (N | A) & $0.270 * * *$ & 9.98 & $0.242 * * *$ & 9.08 \\
\hline Household income (A I SA) & $0.151 * * *$ & 5.62 & $0.125 * * *$ & 4.74 \\
\hline Living with others & $0.144^{*}$ & 1.88 & $0.211 * * *$ & 2.79 \\
\hline Age & $-0.00874 * * *$ & -3.40 & $-0.00632 *$ & -2.50 \\
\hline Age squared & $0.000772 * * *$ & 4.30 & $0.000786^{* * *}$ & 4.42 \\
\hline Female & $0.176^{* * *}$ & 3.03 & $0.220^{* * *}$ & 3.82 \\
\hline Education & $0.0973 * * *$ & 3.93 & $0.0796^{* * *}$ & 3.26 \\
\hline Manager & $0.254 * * *$ & 3.40 & $0.266^{* * *}$ & 3.58 \\
\hline \multicolumn{5}{|l|}{ Travel-related } \\
\hline Have a driver's license & $0.496 * * *$ & 3.11 & $0.381 * *$ & 2.40 \\
\hline Commute time & $-0.00261 * *$ & -2.34 & $-0.00450 * * *$ & -4.23 \\
\hline Physical limitation-transit & $-0.288^{*}$ & -1.81 & $-0.375^{* *}$ & -2.36 \\
\hline Physical limitation—walk & $-0.375^{* * *}$ & -3.02 & $-0.350 * * *$ & -2.82 \\
\hline \multicolumn{5}{|l|}{ General attitudes } \\
\hline Like large yard & $0.0736 * * *$ & 2.60 & - & - \\
\hline Car is a symbol & $-0.0587 * *$ & -2.17 & - & - \\
\hline Don't mind being stuck in traffic & $0.145^{* * *}$ & 4.83 & - & - \\
\hline Travel is wasted time & $-0.179 * * *$ & -5.89 & - & - \\
\hline Commute is stressful & $-0.196^{* * *}$ & -6.18 & - & - \\
\hline \multicolumn{5}{|l|}{ Context-control } \\
\hline \multicolumn{5}{|c|}{ Region indicator (base: Northern California ${ }^{a}$ ) } \\
\hline Southern California ${ }^{\mathrm{b}}$ & 0.0797 & 0.72 & 0.0709 & 0.64 \\
\hline Other California regions & $-0.302 * *$ & -2.03 & $-0.274 *$ & -1.86 \\
\hline Unemployment rate (SD | D) & 5.817 & 1.03 & 7.679 & 1.36 \\
\hline Unemployment rate (D | N) & $9.047 * * *$ & 4.35 & $10.768 * * *$ & 5.24 \\
\hline Unemployment rate $(\mathrm{N} \mid \mathrm{A})$ & $5.063 * * *$ & 3.61 & $6.728 * * *$ & 4.90 \\
\hline Unemployment rate (A I SA) & $4.015^{* * *}$ & 2.88 & $5.525 * * *$ & 4.07 \\
\hline From opinion panel & $-0.344 * * *$ & -4.48 & $-0.362 * * *$ & -4.82 \\
\hline \multicolumn{5}{|l|}{ Thresholds } \\
\hline Threshold 1 (SD | D) & $2.391 * * *$ & 4.02 & $1.895 * * *$ & 3.34 \\
\hline Threshold 2 (D | N) & 0.341 & 1.06 & -0.121 & 0.45 \\
\hline Threshold 3 (N I A) & $-0.503 *$ & -1.74 & $-0.926^{* * *}$ & -4.05 \\
\hline Threshold 4 (A I SA) & $-2.845 * * *$ & -9.43 & $-3.183 * * *$ & -13.15 \\
\hline
\end{tabular}


Table 6 (continued)

\begin{tabular}{lcc}
\hline Variable & Model specification with attitudes & $\begin{array}{l}\text { Model specification without } \\
\text { attitudes }\end{array}$ \\
\hline Model summary & & \\
Number of cases & 4,887 & 4,887 \\
Log-likelihood (0) & $-7,865.32$ & $-7,865.32$ \\
Log-likelihood (thresholds) & $-5,572.50$ & $-5,572.50$ \\
Log-likelihood ( $\widehat{\beta})$ & $-5,304.59$ & $-5,393.12$ \\
$\rho^{2}$ (equally-likely base) & 0.3256 & 0.3143 \\
$\rho^{2}$ (thresholds-only base) & 0.0481 & 0.0322 \\
\hline
\end{tabular}

$* * *$ Coefficient is statistically significant at the 0.01 level

**Coefficient is statistically significant at the 0.05 level

*Coefficient is statistically significant at the 0.1 level

Note: For this sample, the shares of each response are strongly disagree (SD): $0.94 \%$, disagree (D): $6.92 \%$, neutral $(\mathrm{N}): 13.75 \%$, agree (A): $58.13 \%$, and strongly agree (SA): $20.26 \%$

${ }^{a}$ Northern California includes the Sacramento Area Council of Governments (SACOG) and the San Francisco-based Metropolitan Transportation Commission (MTC) regional planning areas

${ }^{\mathrm{b}}$ Southern California includes the Los Angeles-based Southern California Association of Governments (SCAG) and the San Diego Association of Governments (SANDAG) regional planning areas

study is only able to account for a small portion of these explanatory variables (Rojas 2006). Despite low overall model fits in the satisfaction domain, these models are still able to provide critical insights into the factors that influence life satisfaction across studies.

This study demonstrates the possibility of utilizing diverse cross-sectional surveys in a specific domain to examine factors that influence a variable across time and space, i.e., life satisfaction in this case. However, such an approach inevitably results in shortcomings of the resultant fused dataset. Although we have implemented various approaches to control for the influence of these limitations, we may expect residual problems to remain. For example, through the survey fusion process, we attempted to avoid the influence of different question wordings by systematic question categorization and careful manual selection of common questions. Despite this, we cannot be certain that we have excluded all wording ambiguities that may have influenced responses. Then, to account for the influence of different sampling methods, we used a context-control variable to distinguish different data sources. However, for certain sampling methods, inherent biases are difficult to remove, e.g., the self-selection bias of web surveys (Bethlehem 2010). In addition, question orders vary across surveys, which may influence respondents' performance on certain questions (Erdogan et al. 2012). Despite these limitations, we believe that the approach shown in this paper can substantially increase the utility of small cross-sectional survey datasets, and thus, can allow for increased contributions to the literature.

\section{Conclusion}

This study develops generalized ordered logit (GOL) models to study the life satisfaction of commuters using a fused dataset of five cross-sectional surveys conducted in California between the years 1992 to 2018. Explanatory variables studied include demographic 
characteristics, travel-related attributes, attitudinal variables, and context-control variables. Regarding demographic characteristics, we find that higher income is associated with higher propensities for life satisfaction, but the same income increment has a greater return on satisfaction for less-satisfied groups. In line with previous studies, we see a U-shaped relationship between age and life satisfaction, suggesting that the lowest life satisfaction tends to occur while individuals are in their 40s. We also find that those who are female, more educated, and those who live with others have increased propensities toward higher life satisfaction.

Regarding travel attributes, we see that increased commute time and mobility limitations (e.g., not having a driver's license, physical limitations) are associated with lower life satisfaction propensities. Since the fused survey dataset is multi-year and multi-region, the model uses GDP per capita and the unemployment rate to control for contextual influences. Results show that GDP per capita is positively associated with life satisfaction. Increased unemployment rates are associated with higher life satisfaction, which might be because the study focuses on employed people, who may feel fortunate compared to their unemployed peers. Moreover, we present a substitution model to demonstrate the usefulness of year and region indicators as context-control variables (albeit having lower explanatory power; see the Appendix) when specific variables such as GDP per capita and unemployment rate are not available. In this latter (context-control indicator) model, we find an increasing trend of life satisfaction over the years, which might relate to the increasing GDP per capita over the years.

Additionally, we find significantly lower mean life satisfaction for online panel respondents compared to those recruited via more traditional approaches, in support of other studies (Blasius and Brandt 2010; Fan and Yan 2010; Szolnoki and Hoffmann 2013) finding that online panel members are not representative of the general population with respect to a number of variables including attitudes. We also see that attitudes significantly improve the model fit, and aid in understanding the influence of latent characteristics on life satisfaction.

Overall, this study explores the influence of a wide range of variables on life satisfaction using a fused dataset. Combining multiple travel survey datasets to model life satisfaction enables analysis of the contextual variables and generalizable conclusions about the impact of the transportation-related attributes and attitudes on life satisfaction. It also, not insignificantly, creates a substantially larger sample, which can improve the precision of estimated parameters and (in other studies) permit segmentations that would not be practical with smaller samples. We hope that this study will serve as a foundation for other researchers in specific domains to explore the approach of fusing multiple survey datasets for the purpose of modeling life satisfaction or other key variables. We especially urge early-career scholars conducting survey-based studies to begin now to consider the possibility of fusing multiple samples in the future, and with an eye to doing so, to give intentional thought to (1) specific questions that could be repeated in multiple surveys, and (2) the need for optimizing uniformity of question and response wording across surveys. Based on our experiences, we recommend the development of a question inventory for common variable selection, as well as the inclusion of relevant context-control variables for models developed using fused datasets.

\section{Appendix}

See Table 7 . 
Table 7 Full-sample model of life satisfaction using context-control indicators

\begin{tabular}{|c|c|c|}
\hline \multirow[t]{2}{*}{ Variable } & \multicolumn{2}{|c|}{ Generalized ordered logit } \\
\hline & Coefficient & $\mathrm{z}$-value \\
\hline \multicolumn{3}{|l|}{ Socioeconomic and demographic } \\
\hline Household income (SD |D) & $0.349 * * *$ & 4.54 \\
\hline Household income (D | N) & $0.314 * * *$ & 10.07 \\
\hline Household income (N | A) & $0.267 * * *$ & 12.61 \\
\hline Household income (A I SA) & $0.165^{* * * *}$ & 7.96 \\
\hline Living with others & $0.229 * * *$ & 3.73 \\
\hline Age (mean-centered) & -0.00182 & -0.92 \\
\hline Age (mean-centered) squared & $0.000771 * * *$ & 5.91 \\
\hline Female & $0.177 * * *$ & 3.88 \\
\hline Education & $0.0744 * * *$ & 3.83 \\
\hline \multicolumn{3}{|l|}{ Travel-related } \\
\hline Have a driver's license & $0.345 * *$ & 2.58 \\
\hline Commute time & $-0.00428 * * *$ & -4.77 \\
\hline \multicolumn{3}{|l|}{ Context-control } \\
\hline Year indicator (SD | D) & -0.0147 & -0.80 \\
\hline Year indicator (D | N) & $0.0244 * * *$ & 3.61 \\
\hline Year indicator $(\mathrm{N} \mid \mathrm{A})$ & $0.0226 * * *$ & 5.08 \\
\hline Year indicator (A I SA) & $0.0512 * * *$ & 12.28 \\
\hline \multicolumn{3}{|c|}{ Region Indicator (Region: Northern California) } \\
\hline Southern California (SD | D) & -0.316 & -0.56 \\
\hline Southern California (D | N) & -0.0354 & -0.35 \\
\hline Southern California (N|A) & 0.00375 & 0.05 \\
\hline Southern California (A I SA) & $0.205^{* * *}$ & 2.97 \\
\hline Other California regions (SD |D) & -0.140 & -0.42 \\
\hline Other California regions $(\mathrm{D} \mid \mathrm{N})$ & -0.106 & -0.69 \\
\hline Other California regions $(\mathrm{N} \mid \mathrm{A})$ & -0.0415 & -0.39 \\
\hline Other California regions (A ISA) & $0.268 * * *$ & 2.65 \\
\hline From opinion panel (SD | D) & $-0.559 * *$ & -2.01 \\
\hline From opinion panel (D | N) & $-0.579 * * *$ & -4.82 \\
\hline From opinion panel (N | A) & $-0.598 * * *$ & -7.64 \\
\hline From opinion panel (A | SA) & $-0.699 * * *$ & -9.64 \\
\hline \multicolumn{3}{|l|}{ Thresholds } \\
\hline Threshold 1 (SD | D) & $2.888 * * *$ & 6.25 \\
\hline Threshold 2 (D | N) & 0.230 & 1.07 \\
\hline Threshold 3 (N | A) & $-0.799 * * *$ & -4.35 \\
\hline Threshold 4 (A I SA) & $-3.596^{* * *}$ & -18.61 \\
\hline \multicolumn{3}{|l|}{ Model summary } \\
\hline Number of cases & & 7,514 \\
\hline Log-likelihood (0) & & $-12,093.32$ \\
\hline Log-likelihood (thresholds) & & $-8,853.27$ \\
\hline Log-likelihood $(\widehat{\beta})$ & & $-8,514.04$ \\
\hline$\rho^{2}$ (equally-likely base) & & 0.2960 \\
\hline$\rho^{2}$ (thresholds-only base) & & 0.0383 \\
\hline
\end{tabular}


Table 7 (continued)

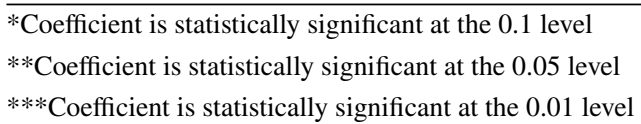

Acknowledgements The authors are grateful to the survey design and implementation teams for the following surveys: 1992 Telecommuting Survey, 1998 Mobility Survey, 2011 Multitasking Northern California Survey, 2015 Millennials Wave 1 Survey, 2016 NCHRP Bicycle Facility Survey, 2017 Georgia Department of Transportation Survey, and 2018 Panel Study of Emerging Transportation Technologies and Trends in California Wave 2 Survey. The original data collections for these surveys were funded by several different agencies, including US DOT, Caltrans, Georgia DOT, the Sustainable Transportation Center, and the National Center for Sustainable Transportation. Any opinions, findings, and conclusions or recommendations expressed in this paper are those of the authors and do not necessarily reflect the views of the sponsor organizations. The comments of the anonymous referees have improved the paper.

Author contributions Study design and direction: XW, FAS, PLM, GC, and KEW. Data collection: PLM and GC. Data analysis: XW. Manuscript drafting: XW and FAS. Manuscript review and editing: PLM, GC, and KEW. All authors approved the final manuscript.

Funding This study was funded under the Teaching Old Models New Tricks (TOMNET) Center, a University Transportation Center sponsored by the US Department of Transportation (DOT) through Grant No. 69A3551747116.

\section{Declarations}

Conflicts of interest The authors have no relevant financial or non-financial interests to disclose.

Open Access This article is licensed under a Creative Commons Attribution 4.0 International License, which permits use, sharing, adaptation, distribution and reproduction in any medium or format, as long as you give appropriate credit to the original author(s) and the source, provide a link to the Creative Commons licence, and indicate if changes were made. The images or other third party material in this article are included in the article's Creative Commons licence, unless indicated otherwise in a credit line to the material. If material is not included in the article's Creative Commons licence and your intended use is not permitted by statutory regulation or exceeds the permitted use, you will need to obtain permission directly from the copyright holder. To view a copy of this licence, visit http://creativecommons.org/licenses/by/4.0/.

\section{References}

Ajzen, I.: Attitudes, Personality, and Behavior. Open University Press, London, UK (2005)

Atroszko, P.A., Sawicki, A., Mąkinia, A., Atroszko, B.: Further validation of single-item self-report measure of satisfaction with life. In: Proceedings of the 7th Biannual CER Comparative European Research Conference. London, UK. March 29-31, 2017. (2017) Available at https://depot.ceon.pl/bitstream/handle/123456789/11883/Further\%20validation\%20of\%20single-item $\% 20$ self-report $\% 20$ measure $\% 20$ of $\%$ 20satisfaction \%20with\%20life.pdf?sequence=1\&isAllowed=y

Banister, D., Bowling, A.: Quality of life for the elderly: the transport dimension. Transp. Policy 11, 105115 (2004)

Bethlehem, J.: Selection bias in web surveys. Int. Stat. Rev. 78(2), 161-188 (2010)

Beutel, M.E., Glaesmer, H., Wiltink, J., Marian, H., Brähler, E.: Life satisfaction, anxiety, depression and resilience across the life span of men. Aging Male 13(1), 32-39 (2010)

Blanchflower, D.G., Oswald, A.J.: Well-being over time in Britain and the USA. J. Public Econ. 88(7-8), 1359-1386 (2004)

Blanchflower, D.G., Oswald, A.J.: Is well-being U-shaped over the life cycle? Soc. Sci. Med. 66(8), 17331749 (2008) 
Blasius, J., Brandt, M.: Representativeness in online surveys through stratified samples. Bull. Sociol. Methodol./bulletin De Methodologie Sociologique 107(1), 5-21 (2010)

Cheung, F., Lucas, R.E.: Assessing the validity of single-item life satisfaction measures: Results from three large samples. Qual. Life Res. 23(10), 2809-2818 (2014)

Circella, G., Fulton, L., Alemi, F., Berliner, R.M., Tiedeman, K., Mokhtarian, P.L., Handy, S.: What affects millennials' mobility? PART I: Investigating the environmental concerns, lifestyles, mobility-related attitudes and adoption of technology of young adults in California. Institute of Transportation Studies, University of California, Davis. (2016) Available at http://www.dot.ca.gov/research/researchreports/ reports/2016/CA16-2825_FinalReport.pdf.

Circella, G., Matson, G., Alemi, F., Handy, S.: Panel study of emerging transportation technologies and trends in California: Phase 2 data collection. National Center for Sustainable Transportation, University of California, Davis. (2019) Available at https://escholarship.org/uc/item/35x894mg

Cracolici, M.F., Giambona, F., Cuffaro, M.: Family structure and subjective economic well-being: Some new evidence. Soc. Indic. Res. 118(1), 433-456 (2014)

Cummins, R.A.: Measuring population happiness to inform public policy. Paper presented at the The 3rd OECD World Forum on "Statistics, Knowledge and Policy" Charting Progress, Building Visions, Improving Life, Busan, Korea (2009)

Curry, R.: Attitudes toward travel: the relationships among perceived mobility, travel liking, and relative desired mobility. Master's Thesis, Department of Civil and Environmental Engineering, University of California, Davis (2000)

De Vos, J., Schwanen, T., Van Acker, V., Witlox, F.: Travel and subjective well-being: a focus on findings, methods and future research needs. Transp. Rev. 33(4), 421-442 (2013)

Dean, L., Phillips, M.: Attitudes to mental health problems and mental wellbeing: findings from the 2015 British social attitudes survey. (2015) Retrieved from http://www.bsa.natcen.ac.uk/media/39109/phebsa-2015-attitudes-to-mental-health.pdf

Deaton, A.: Income, health, and well-being around the world: evidence from the Gallup World Poll. Journal of Economic Perspectives 22(2), 53-72 (2008). https://doi.org/10.1257/jep.22.2.53

DeNeve, K.M., Cooper, H.: The happy personality: a meta-analysis of 137 personality traits and subjective well-being. Psychol. Bull. 124(2), 197-229 (1998)

Di Tella, R., MacCulloch, R.J., Oswald, A.J.: Preferences over inflation and unemployment: evidence from surveys of happiness. American Economic Review 91(1), 335-341 (2001)

Dickerson, A., Hole, A.R., Munford, L.A.: The relationship between well-being and commuting revisited: does the choice of methodology matter? Reg. Sci. Urban Econ. 49, 321-329 (2014). https://doi.org/10. 1016/j.regsciurbeco.2014.09.004

Diener, E.: Subjective well-being. Psychol. Bull. 95(3), 542-575 (1984)

Diener, E.: Subjective well-being: The science of happiness and a proposal for a national index. Am. Psychol. 55(1), 34-41 (2000)

Diener, E., Biswas-Diener, R.: Will money increase subjective well-being? Soc. Indic. Res. 57(2), 119-169 (2002)

Diener, E., Gohm, C.L., Suh, E., Oishi, S.: Similarity of the relations between marital status and subjective well-being across cultures. J. Cross Cult. Psychol. 31(4), 419-436 (2000)

Diener, E., Kahneman, D., Tov, W., Arora, R.: Income's association with judgments of life versus feelings. In: Diener, E., Kahneman, D., Helliwell, J.F. (eds.) International Differences in Well-being, pp. 3-15. Oxford University Press, Oxford UK (2010)

Diener, E., Oishi, S.: Money and happiness: Income and subjective well-being across nations. In: Diener, E., Suh, E.M. (eds.) Culture and Subjective Well-being, pp. 185-218. The MIT Press, Cambridge, MA, US (2000)

Diener, E., Oishi, S., Lucas, R.E.: Personality, culture, and subjective well-being: emotional and cognitive evaluations of life. Ann Rev. Psychol. 54(1), 403-425 (2003)

Enders, C.K.: Centering predictors and contextual effects. In: Scott, M.A., Simonoff, J.S., Marx, B.D. (eds.) The SAGE Handbook of Multilevel Modeling, pp. 89-108. SAGE Publications Ltd, London (2016)

Erdogan, B., Bauer, T.N., Truxillo, D.M., Mansfield, L.R.: Whistle while you work: a review of the life satisfaction literature. J. Manag. 38(4), 1038-1083 (2012)

Eriksson, L., Friman, M., Gärling, T.: Perceived attributes of bus and car mediating satisfaction with the work commute. Transp. Res. Part A 47, 87-96 (2013)

Fan, W., Yan, Z.: Factors affecting response rates of the web survey: A systematic review. Comput. Hum. Behav. 26(2), 132-139 (2010). https://doi.org/10.1016/j.chb.2009.10.015

Frey, B.S., Stutzer, A.: Happiness, economy and institutions. Econ. J. 110(466), 918-938 (2000)

Gärling, T., Gamble, A.: Life satisfaction and emotional well-being: psychological, economic and social factors. In: Ranyard, R. (ed.) Economic psychology, p. 405-420. John Wiley \& Sons, West Sussex, UK (2018) 
Greene, W.H.: Econometric Analysis, 8th edn. Prentice-Hall, Upper Saddle River, NJ (2018)

Hansen, J.L., Formby, J.P., Smith, W.J.: Estimating the income elasticity of demand for housing: A comparison of traditional and Lorenz-concentration curve methodologies. J. Hous. Econ. 7(4), 328-342 (1998)

Hartley-Clark, L.: Investigating the Affective Core of SWB: the Circular Way. PhD thesis, Deakin University (2014)

Heller, D., Watson, D., Ilies, R.: The dynamic process of life satisfaction. J. Pers. 74(5), 1421-1450 (2006)

Helliwell, J.F., Putnam, R.D.: The social context of well-being. Philos. Trans. Royal Soc. B: Biol. Sci. 359(1449), 1435-1446 (2004)

Hilbrecht, M., Smale, B., Mock, S.E.: Highway to health? Commute time and well-being among Canadian adults. World Leis. J. 56(2), 151-163 (2014)

Huta, V., Ryan, R.M.: Pursuing pleasure or virtue: The differential and overlapping well-being benefits of hedonic and eudaimonic motives. J. Happiness Stud. 11(6), 735-762 (2010)

Ifcher, J., Zarghamee, H.: The happiness of single mothers: Evidence from the General Social Survey. J. Happiness Stud. 15(5), 1219-1238 (2014)

Jovanović, V.: The validity of the Satisfaction with Life Scale in adolescents and a comparison with singleitem life satisfaction measures: a preliminary study. Qual. Life Res. 25(12), 3173-3180 (2016)

Kelley, J., Evans, M.: Societal inequality and individual subjective well-being: Results from 68 societies and over 200,000 individuals, 1981-2008. Soc. Sci. Res. 62, 1-23 (2017)

Kim, D.: Cross-national pattern of happiness: do higher education and less urbanization degrade happiness? Appl. Res. Qual. Life 13(1), 21-35 (2018)

Kim, S.H., Mokhtarian, P.L., Circella, G.: The Impact of Emerging Technologies and Trends on Travel Demand in Georgia (No. FHWA-GA-19-1631). Georgia Institute of Technology (2019). https://rosap. ntl.bts.gov/view/dot/56095

Levin, J.: Religion and happiness among Israeli Jews: findings from the ISSP religion III survey. J. Happiness Stud. 15(3), 593-611 (2014)

Lorenz, O.: Does commuting matter to subjective well-being? J. Transp. Geogr. 66, 180-199 (2018)

Lucas, R.E., Donnellan, M.B.: How stable is happiness? Using the STARTS model to estimate the stability of life satisfaction. J. Res. Pers. 41(5), 1091-1098 (2007)

Marmot, M.: The influence of income on health: views of an epidemiologist. Health Aff. 21(2), 31-46 (2002)

Martin, A., Goryakin, Y., Suhrcke, M.: Does active commuting improve psychological wellbeing? Longitudinal evidence from eighteen waves of the British Household Panel Survey. Prev. Med. 69, 296-303 (2014)

McCarthy, S., Habib, M.A.: Investigation of life satisfaction, travel, built environment, and attitudes. J. Transp. Health 11, 15-24 (2018)

McLaughlin, K.A., Kubzansky, L.D., Dunn, E.C., Waldinger, R., Vaillant, G., Koenen, K.C.: Childhood social environment, emotional reactivity to stress, and mood and anxiety disorders across the life course. Depress. Anxiety 27(12), 1087-1094 (2010)

Mokhtarian, P.L.: Discrete choice models' $\rho 2$ : a reintroduction to an old friend. J. Choice Modell. 21, 60-65 (2016)

Mokhtarian, P.L.: Subjective well-being and travel: retrospect and prospect. Transportation 46(2), 493-513 (2019)

Mokhtarian, P.L., Salomon, I.: Modeling the choice of telecommuting: a case of the preferred impossible alternative. Environ. Plann. A 28(10), 1859-1876 (1996)

Morris, E.A., Guerra, E.: Mood and mode: does how we travel affect how we feel? Transportation 42(1), 25-43 (2015)

Morrison, P.S., Weckroth, M.: Human values, subjective well-being and the metropolitan region. Reg. Stud. 52(3), 325-337 (2018)

Morton, L.M., Cahill, J., Hartge, P.: Reporting participation in epidemiologic studies: a survey of practice. Am. J. Epidemiol. 163(3), 197-203 (2005)

National Research Council: Nonresponse in Social Science Surveys: A Research Agenda. National Academies Press, Washington (2013)

Neufeld, A.J., Mokhtarian, P.L.: A Survey of Multitasking by Northern California Commuters: Description of the Data Collection Process. Institute of Transportation Studies. University of California, Davis. (2012) Available at http://pubs.its.ucdavis.edu/download_pdf.php?id=1802

Nie, P., Sousa-Poza, A.: Commute time and subjective well-being in urban China. China Econ. Rev. 48, 188-204 (2016)

Nikolaev, B.: Living with mom and dad and loving it... or are you? J. Econ. Psychol. 51, 199-209 (2015)

Nikolaev, B.: Does Higher Education Increase Hedonic and Eudaimonic Happiness? J. Happiness Stud. 19(2), 483-504 (2018) 
Ochsen, C.: Subjective well-being and aggregate unemployment: further evidence. Scott. J. Polit. Econ. 58(5), 634-655 (2011)

Oishi, S.: The concept of life satisfaction across cultures: an IRT analysis. J. Res. Pers. 40(4), 411-423 (2006)

Olivos, F., Olivos-Jara, P., Browne, M.: Asymmetric social comparison and life satisfaction in social networks. J. Happiness Stud. 22, 363-384 (2020)

Ortiz-Ospina, E., Roser, M.: Happiness and life satisfaction. Published online at OurWorldInData.org. (2018) Available at https://ourworldindata.org/happiness-and-life-satisfaction

Oswald, A.J., Wu, S.: Objective confirmation of subjective measures of human well-being: Evidence from the USA. Science 327(5965), 576-579 (2010)

Pavot, W., Diener, E.: Review of the satisfaction with life scale. Psychol. Assess. 5(2), 164-172 (1993)

Pickett, K.E., Wilkinson, R.G.: Income inequality and health: a causal review. Soc. Sci. Med. 128, 316-326 (2015)

Requena, F.: Rural-urban living and level of economic development as factors in subjective well-being. Soc. Indic. Res. 128(2), 693-708 (2016)

Rojas, M.: Life satisfaction and satisfaction in domains of life: Is it a simple relationship? J. Happiness Stud. 7(4), 467-497 (2006)

Rosenberg, S.D., Rosenberg, H.J., Farrell, M.P.: The midlife crisis revisited. In: Willis, S.L., Reid, J.D. (eds.) Life in the middle: psychological and social development in middle age. Academic Press, San Diego (1999)

Ryan, R.M., Deci, E.L.: On happiness and human potentials: a review of research on hedonic and eudaimonic well-being. Annu. Rev. Psychol. 52(1), 141-166 (2001)

Sander, W.: Location and happiness in the United States. Econ. Lett. 112(3), 277-279 (2011)

Sarracino, F.: Social capital and subjective well-being trends: comparing 11 western European countries. J. Socio-Econ. 39(4), 482-517 (2010)

Shaw, F.A., Malokin, A., Mokhtarian, P.L., Circella, G.: It's not all fun and games: an investigation of the reported benefits and disadvantages of conducting activities while commuting. Travel Behaviour and Society 17, 8-25 (2019)

Shields, M., Wooden, M.: Marriage, children and subjective well-being. Presented at the 8th Australian Institute of Family Studies Conference. Melbourne, Australia (2003)

Shields, M.A., Price, S.W., Wooden, M.: Life satisfaction and the economic and social characteristics of neighbourhoods. J. Popul. Econ. 22(2), 421-443 (2009)

Smith, O.: Commute well-being differences by mode: evidence from Portland, Oregon, USA. J. Transp. Health 4, 246-254 (2017)

Soto, C.J.: Is happiness good for your personality? Concurrent and prospective relations of the big five with subjective well-being. J. Pers. 83(1), 45-55 (2015)

St-Louis, E., Manaugh, K., van Lierop, D., El-Geneidy, A.: The happy commuter: a comparison of commuter satisfaction across modes. Transp. Res. Part F 26, 160-170 (2014)

Stevenson, B., Wolfers, J.: Economic Growth and Subjective Well-being: Reassessing the Easterlin Paradox. CESifo Working Paper, No. 2394, Center for Economic Studies and Ifo Institute (CESifo), Munich (2008)

Stutzer, A., Frey, B.S.: Stress that doesn't pay: the commuting paradox. Scand. J. Econ. 110(2), 339-366 (2008)

Sweet, M., Kanaroglou, P.: Gender differences: the role of travel and time use in subjective well-being. Transp. Res. Part F 40, 23-34 (2016)

Szolnoki, G., Hoffmann, D.: Online, face-to-face and telephone surveys-comparing different sampling methods in wine consumer research. Wine Economics and Policy 2(2), 57-66 (2013)

Waldinger, R.J., Vaillant, G.E., Orav, E.J.: Childhood sibling relationships as a predictor of major depression in adulthood: A 30-year prospective study. Am. J. Psychiatry 164(6), 949-954 (2007)

Welsch, H., Kuehling, J.: Divided We Stand: Immigration Attitudes, Identity, and Subjective Well-Being. Oldenburg Discussion Papers in Economics, No. V-401-17, University of Oldenburg, Department of Economics, Oldenburg.

Wener, R.E., Evans, G.W.: Comparing stress of car and train commuters. Transp. Res. Part F 14(2), 111116 (2011)

Williams, R.: Generalized ordered logit/partial proportional odds models for ordinal dependent variables. Stata Journal 6(1), 58 (2006)

Williams, R.: Understanding and interpreting generalized ordered logit models. J. Math. Sociol. 40(1), 7-20 (2016)

Witter, R.A., Okun, M.A., Stock, W.A., Haring, M.J.: Education and subjective well-being: a meta-analysis. Educ. Eval. Policy Anal. 6(2), 165-173 (1984) 
Yakovlev, P., Leguizamon, S.: Ignorance is not bliss: on the role of education in subjective well-being. J. Socio-Econ. 41(6), 806-815 (2012)

Publisher's Note Springer Nature remains neutral with regard to jurisdictional claims in published maps and institutional affiliations.

Xinyi Wang is a Ph.D. candidate at Georgia Institute of Technology (Georgia Tech) specializing in Transportation Systems and Engineering. She holds a B.Eng in Transportation Engineering from Southeast University, Nanjing, China and a M.Sc in Civil Engineering from Georgia Tech. Xinyi is currently working on her second M.Sc degree in Statistics. Her research interests include travel behavior, survey method, and statistical modeling.

F. Atiyya Shaw is currently a Postdoctoral Fellow in the Department of City and Regional Planning at U.C. Berkeley. She holds a B.Sc., M.Sc., and Ph.D. in Civil Engineering, and an M.Sc. in Psychometrics. Her research is focused on data and methods that prioritize user-centered outcomes in transport engineering and urban planning.

Patricia L. Mokhtarian is the Clifford and William Greene, Jr. Professor of Civil and Environmental Engineering at the Georgia Institute of Technology, specializing in the application of quantitative methods to the study of travel behavior for more than 40 years. She is a Past Chair of the International Association for Travel Behaviour Research, and was the 2021 recipient of its Lifetime Achievement Award.

Giovanni Circella is a Senior Research Engineer in the School of Civil and Environmental Engineering of the Georgia Institute of Technology, and the Honda Distinguished Scholar for New Mobility Studies and Director of the 3 Revolutions Future Mobility Program at the University of California, Davis. Dr. Circella's research interests include travel behavior, travel demand modeling, travel survey methods, shared mobility and emerging transportation services, autonomous vehicles, sustainable transportation and policy analysis.

Kari E. Watkins, P.E., is the Frederick Law Olmsted Associate Professor in the School of Civil and Environmental Engineering at the Georgia Institute of Technology. Her teaching and research interests revolve around multi-modal transportation planning and the use of technology in transportation, especially as related to transit planning and operations and improved traveler information.

\section{Authors and Affiliations}

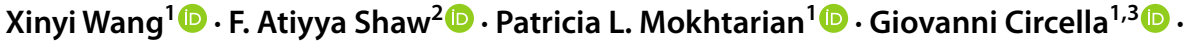 Kari E. Watkins ${ }^{1}$}

F. Atiyya Shaw

atiyya@berkeley.edu

Patricia L. Mokhtarian

patmokh@gatech.edu

Giovanni Circella

giovanni.circella@ce.gatech.edu

Kari E. Watkins

kari.watkins@ce.gatech.edu

1 School of Civil and Environmental Engineering, Georgia Institute of Technology, 790 Atlantic Drive, Atlanta, GA 30332, USA

2 Department of City and Regional Planning, University of California, Berkeley, CA 94720, USA

3 Institute of Transportation Studies, University of California, 1715 Tilia Street, Davis, CA 95616, USA 